\title{
Dual Bronchodilator Therapy as First-Line Treatment in Maintenance-Naïve Patients with Symptomatic COPD: A Pre-Specified Analysis of the EMAX Trial
}

\author{
Leif Bjermer (D) \\ Isabelle H Boucot (iD) ${ }^{2}$ \\ François Maltais (D) ${ }^{3}$ \\ Edward M Kerwin (iD) 4 \\ Ian P Naya ${ }^{2}$ \\ Lee Tombs ${ }^{5}$ \\ Paul W Jones id ${ }^{2}$ \\ Chris Compton ${ }^{2}$ \\ David A Lipson (D) 6,7 \\ Claus F Vogelmeier ${ }^{8}$ \\ 'Respiratory Medicine and Allergology, \\ Lund University, Lund, Sweden; ${ }^{2}$ Global \\ Specialty \& Primary Care, GSK, \\ Brentford, Middlesex, UK; ${ }^{3}$ Centre de \\ Pneumologie, Institut Universitaire de \\ Cardiologie et de Pneumologie de \\ Québec, Université Laval, Québec, \\ Canada; ${ }^{4}$ Clinical Research Institute of \\ Southern Oregon, Medford, OR, USA; \\ ${ }^{5}$ Precise Approach Ltd, contingent \\ worker on assignment at GSK, Stockley \\ Park West, Uxbridge, Middlesex, UK; \\ ${ }^{6}$ Respiratory Clinical Sciences, GSK, \\ Collegeville, PA, USA; ${ }^{7}$ Perelman School \\ of Medicine, University of Pennsylvania, \\ Philadelphia, PA, USA; ${ }^{8}$ Department of \\ Medicine, Pulmonary and Critical Care \\ Medicine, University Medical Center \\ Giessen and Marburg, Philipps- \\ Universität Marburg, Member of the \\ German Center for Lung Research \\ (DZL), Marburg, Germany
}

Correspondence: Leif Bjermer Respiratory Medicine and Allergology, Skane University Hospital, 22I 85 Lund, Sweden

Tel +46 46 I7 2325

Email leif.bjermer@med.lu.se
Introduction: Limited prospective evidence is available to guide selection of first-line maintenance therapy in patients with COPD. This pre-specified analysis of the EMAX trial explored the efficacy and safety of dual- versus mono-bronchodilator therapy in maintenance-naïve and maintenance-treated patients.

Methods: The 24-week EMAX trial evaluated lung function, symptoms (including rescue medication use), exacerbations, and safety with umeclidinium/vilanterol, umeclidinium, and salmeterol in symptomatic patients at low exacerbation risk who were not receiving inhaled corticosteroids. Maintenance-naïve and maintenance-treated subgroups were defined by maintenance bronchodilator use 30 days before screening.

Results: The analysis included 749 (31\%) maintenance-naïve and 1676 (69\%) maintenancetreated patients. For both subgroups, improvements from baseline in trough $\mathrm{FEV}_{1}$ at Week 24 (primary endpoint) were greater with umeclidinium/vilanterol versus umeclidinium (mean difference [95\% CI]; maintenance-naïve: $44 \mathrm{~mL}$ [1, 87]; maintenance-treated: $77 \mathrm{~mL}[50,104])$, and salmeterol (maintenance-naïve: $128 \mathrm{~mL}$ [85, 171]; maintenance-treated: $145 \mathrm{~mL}[118,172]$ ), and in rescue medication inhalations/day over 24 weeks versus umeclidinium (maintenance-naïve: -0.44 $[-0.73,-0.16]$; maintenance-treated: $-0.28[-0.45,-0.12])$ and salmeterol (maintenance-naïve: -0.37 [ $-0.66,-0.09]$; maintenance-treated: -0.25 [ $-0.41,-0.08]$ ). In maintenance-naïve patients, umeclidinium/vilanterol numerically improved scores at Week 24 for Transition Dyspnea Index versus umeclidinium $(0.37[-0.21,0.96])$ and versus salmeterol $(0.47[-0.10,1.05])$ and Evaluating Respiratory Symptoms-COPD versus umeclidinium $(-0.26[-1.04,0.53])$ and versus salmeterol $(-0.58[-1.36,0.20])$, with similar improvements seen in maintenance-treated patients. All treatments were well tolerated across both subgroups.

Conclusion: Similar to maintenance-treated patients, maintenance-naïve patients receiving umeclidinium/vilanterol showed greater improvements in lung function and symptoms compared with patients receiving umeclidinium or salmeterol. These findings provide support for the consideration of dual bronchodilator treatment in symptomatic maintenance-naïve patients with COPD.

Keywords: COPD treatment, first-line therapy, maintenance-naïve, umeclidinium/vilanterol, umeclidinium, salmeterol

\section{Plain Language Summary}

Why was study done?

Many patients with chronic obstructive pulmonary disease (COPD) require daily medication, known as maintenance treatment, to help achieve long-term disease control. The Global Initiative for Chronic Obstructive Lung Disease strategy recommends that most of 
these patients are initially treated with one long-term bronchodilator medication, and are prescribed a second bronchodilator if their symptoms persist or worsen. However, initiating treatment with two bronchodilators may be appropriate for symptomatic patients with COPD, and may lead to better outcomes.

\section{What did researchers do/find?}

We analyzed data from a clinical trial (EMAX) that compared the relative benefits of a combination of two bronchodilators, umeclidinium/vilanterol (UMEC/VI), with a single bronchodilator (either UMEC or salmeterol [SAL]) over 6 months. In this analysis, we looked specifically at patients who had not been receiving any other maintenance treatment for COPD in the month before enrollment in the trial (maintenancenaïve), and patients who had received maintenance treatment in the month before the trial (maintenance-treated). We found that maintenance-naïve and maintenance-treated patients receiving UMEC/VI had better lung function and improved symptoms, were less dependent on their reliever inhaler, and were less likely to experience disease worsening than patients receiving UMEC or SAL.

\section{What do these results mean?}

A combination of two bronchodilators, such as UMEC/VI, may be better than a single bronchodilator for treating symptomatic patients with COPD, whether or not they have previously received maintenance treatment. Physicians should consider prescribing a combination of two bronchodilators as initial treatment for patients with significant symptom burden who have not previously received long-term maintenance treatment for COPD.

\section{Introduction}

Many patients with chronic obstructive pulmonary disease (COPD) remain symptomatic while on one long-acting bronchodilator. ${ }^{1}$ It is well established that COPD symptoms have a detrimental impact on health status and quality of life, with many symptomatic patients also experiencing anxiety and/or depression. ${ }^{2,3}$ Furthermore, symptomatic patients are at increased risk of exacerbations and have poorer disease prognosis than those with wellcontrolled symptoms. ${ }^{4,5}$

Meta-analyses of clinical trial data have shown that dual long-acting muscarinic antagonist (LAMA)/long-acting $\beta_{2^{-}}$ agonist (LABA) combination therapies provide greater improvements in lung function, symptoms, and health-related quality of life, as well as a reduced risk of exacerbations compared with LAMA or LABA monotherapy. ${ }^{6-9}$ Furthermore, dual LAMA/LABA therapies have a similar safety profile to LAMA or LABA monotherapies, with no apparent increase in the incidence of serious adverse events (SAEs). ${ }^{7}$ As such, dual long-acting bronchodilators may be an appropriate option for initial maintenance therapy in symptomatic patients. In recognition of this, the American Thoracic Society has made a strong recommendation for the use of LAMA/LABA combination therapy over LAMA or LABA monotherapy in patients with COPD and dyspnea or exercise intolerance. ${ }^{10}$ In addition, some national guidelines, including those provided by the UK National Institute for Health and Care Excellence, recommend dual bronchodilator treatment as first-line therapy in certain patients, such as those without features suggesting steroid responsiveness or asthma, who remain breathless or experience exacerbations despite use of short-acting bronchodilators. ${ }^{11}$ In contrast, for patients with symptomatic COPD and low risk of exacerbations the Global Initiative for Chronic Obstructive Lung Disease (GOLD) recommends initial maintenance treatment with LAMA or LABA monotherapy, or LAMA/LABA dual therapy for those with severe breathlessness. ${ }^{12}$ Current recommendations for first-line LAMA/LABA use are therefore inconsistent, and have been formulated based on limited evidence from clinical trials in patients already receiving maintenance therapy, often combination treatments, and usually in the absence of any prospective data on the efficacy of dual bronchodilators as firstline maintenance therapy. Available evidence to guide clinicians in their choice of first-line therapy for patients with COPD is therefore limited.

Previous studies suggest that a considerable population of patients have a significant symptom burden and exacerbation risk and yet do not receive regular maintenance therapy and remain maintenance-naïve $(\mathrm{MN}){ }^{13-15}$ Post hoc evidence in MN patients indicates that dual bronchodilator therapy may have larger beneficial effects on lung function, symptoms, health status, rescue medication use, and COPD stability compared with monotherapy. ${ }^{13,15-17}$ Early initiation of LAMA/ LABA therapy may therefore improve outcomes for symptomatic patients with COPD; however, prospective studies are required to corroborate this.

The Early MAXimization of bronchodilation for improving COPD stability (EMAX) trial investigated the efficacy and safety of umeclidinium/vilanterol (UMEC/VI; LAMA/LABA), umeclidinium (UMEC; LAMA), and salmeterol (SAL; LABA) in symptomatic patients with COPD at low risk of exacerbation who were not receiving inhaled corticosteroids (ICS). ${ }^{18}$ In this pre-specified subgroup analysis, clinical benefits and safety of UMEC/VI compared with UMEC and SAL were evaluated in $\mathrm{MN}$ patients and in patients who were receiving maintenance treatment prior to the start of the study (maintenancetreated $[\mathrm{MT}]$ patients). A secondary aim of this analysis 
was to observe the mean improvements from baseline with $\mathrm{UMEC} / \mathrm{VI}$, UMEC, or SAL in MN and MT patients.

\section{Materials and Methods Study Design}

The multicenter, double-blind, double-dummy, 3-arm parallel-group EMAX trial randomized patients 1:1:1 to 24 weeks of UMEC/VI $(62.5 / 25 \mu \mathrm{g})$ once daily via the ELLIPTA inhaler, UMEC $(62.5 \mu \mathrm{g})$ once daily via ELLIPTA, or SAL $(50 \mu \mathrm{g})$ twice-daily via the DISKUS inhaler. The trial was conducted between June 2017 and June 2018, and full details of the study design have been published previously. ${ }^{18}$

This study was performed according to the Declaration of Helsinki and received appropriate ethical approval (Supplementary Table S1). All patients provided written informed consent via a form signed at either the Prescreening or Screening visit.

\section{Patients}

Eligible patients were $\geq 40$ years of age and were current or former smokers with a diagnosis of COPD, pre- and postalbuterol forced expiratory volume in 1 second/forced vital capacity $\left(\mathrm{FEV}_{1} / \mathrm{FVC}\right)$ ratio $<0.7$, post-albuterol $\mathrm{FEV}_{1}$ of $\geq 30-80 \%$ predicted (corresponding to GOLD grade 2 or 3 ), COPD Assessment Test (CAT) score $\geq 10$, and $\leq 1$ moderate and no severe exacerbations in the previous year. Prior to screening and during the 4-week run-in period, treatment with $\leq 1$ maintenance bronchodilator monotherapy (LAMA or LABA) was permitted, with all eligible patients continuing to be symptomatic (CAT score $\geq 10$ ) on their run-in treatments. Patients had no ICS or ICS/LABA treatment for $\geq 6$ weeks prior to run-in, and no LAMA/LABA combination therapy for $\geq 2$ weeks prior to run-in. After the run-in period, study treatment was given for 24 weeks.

For this analysis, MN and MT subgroups were defined by maintenance bronchodilator use during the period from 30 days prior to screening until the first dose of study treatment. Over this period, $\mathrm{MN}$ patients did not receive any COPD maintenance medications except for shortacting bronchodilators as rescue medication.

\section{Endpoints}

This secondary analysis of the EMAX trial included spirometry, patient-reported outcomes (PROs), exacerbations, shortterm disease stability (clinically important deteriorations [CID]), and safety outcomes. Spirometry assessments comprised change from baseline in trough $\mathrm{FEV}_{1}, \mathrm{FVC}$, and inspiratory capacity (IC). PROs comprised change from baseline for self-administered computerized Transition Dyspnea Index (SAC-TDI) focal score, Evaluating Respiratory Symptoms-COPD (E-RS) total score, rescue medication use (including inhalations/day and the proportion of rescue-free days), global assessment of disease severity (GADS), St George's Respiratory Questionnaire (SGRQ) total score, and CAT total score. Response rates were calculated based on the proportion of individual patients with a $\geq 1$-unit improvement in SAC-TDI score, $\geq 2$-point reduction in E-RS score from baseline, $\geq 4$-point reduction in SGRQ score from baseline, and $\geq 2$-unit improvement in CAT score from baseline. Shortterm disease worsening outcomes included time to first moderate/severe exacerbation and risk of a first CID. For individual patients, risk of a first CID was assessed using three different composite definitions. Definition 1 comprised a first moderate or severe exacerbation, and/or a decrease in trough $\mathrm{FEV}_{1}$ from baseline of $\geq 100 \mathrm{~mL}$, and/or a deterioration in health status indicated by an increase in SGRQ score from baseline of $\geq 4$ units. Definition 2 was similar to Definition 1, except that a CAT deterioration ( $\geq 2$ units from baseline) replaced the SGRQ deterioration. Definition 3 comprised a first moderate or severe exacerbation, and/or a SGRQ deterioration, and/or a CAT deterioration, and/or a SAC-TDI deterioration indicated by a decrease of $\geq 1$ unit. Safety was assessed based on the incidence of adverse events (AEs) and SAEs.

\section{Statistical Analysis}

The EMAX trial was powered to detect differences between treatments for trough $\mathrm{FEV}_{1}$ and SAC-TDI at Week 24 in the intent-to-treat (ITT) population; however, the trial was not powered to detect treatment differences in the smaller maintenance treatment subgroups. For this reason, treatment differences with 95\% confidence intervals (CI) are described without reference to statistical significance within subgroups, although $P$-values are presented in the figures and tables.

Full details of the statistical analyses have been reported previously. ${ }^{18}$ Comparisons of change from baseline in lung function and PROs used mixed model repeated measures (MMRM) analyses. Least squares (LS) mean and LS mean change from baseline with estimated treatment differences are reported with 95\% CIs. Response rates were compared using generalized linear mixed model analyses, and odds ratios (OR) with 95\% CIs are reported. For time to first CID, hazard ratios (HR) and 95\% CIs were calculated using a Cox proportional hazards model. A full description of the covariates included in each model is included in the Supplementary Methods. 
Table I Baseline Demographics and Clinical Characteristics

\begin{tabular}{|c|c|c|c|}
\hline & ITT $(\mathrm{N}=\mathbf{2 4 2 5})$ & $M N(N=749)$ & $M T(N=1676)$ \\
\hline Age, years, mean (SD) & $64.6(8.5)$ & $63.0(8.3)$ & $65.4(8.4)$ \\
\hline Female, $\mathrm{n}(\%)$ & $988(4 I)$ & $343(46)$ & $645(38)$ \\
\hline Current smoker, n (\%) & $1203(50)$ & $493(66)$ & $710(42)$ \\
\hline Smoking pack-years, mean (SD) & $48.4(26.5)$ & $49.9(25.2)$ & $47.7(27.0)$ \\
\hline Duration of COPD, years, mean (SD) & $8.3(6.6)$ & $8.3(6.8)$ & $8.3(6.5)$ \\
\hline Moderate COPD exacerbation in past 12 months $^{\mathrm{a}}, \mathrm{n}(\%)$ & $393(16)$ & $77(10)$ & $316(19)$ \\
\hline Post-albuterol percent predicted $\mathrm{FEV}_{1}$, mean (SD) & $55.4(12.7)$ & $57.0(12.3)$ & $54.7(12.9)$ \\
\hline Post-albuterol $\mathrm{FEV}_{\mathrm{I}} / \mathrm{FVC}$, mean (SD) & $0.52(0.10)$ & $0.54(0.10)$ & $0.51(0.10)$ \\
\hline Percent reversibility to albuterol, mean (SD) & $10.5(13.1)$ & $12.8(12.8)$ & $9.4(13.1)$ \\
\hline \multicolumn{4}{|l|}{ GOLD grade ${ }^{b}, n(\%)$} \\
\hline 2 & $1569(65)$ & $526(70)$ & $1043(62)$ \\
\hline 3 & $851(35)$ & $222(30)$ & $629(38)$ \\
\hline Baseline $\mathrm{FEV}_{\mathrm{l}}, \mathrm{mL}$, mean $(\mathrm{SD})$ & $|49|(5 \mid 7)$ & $|54|(53 \mid)$ & 1468 (509) \\
\hline BDI focal score, mean (SD) & $7.0(1.9)$ & $7.1(2.0)$ & $7.0(1.8)$ \\
\hline E-RS total score, mean (SD) & $10.6(5.7)$ & $11.6(6.0)$ & $10.2(5.5)$ \\
\hline SGRQ score, mean (SD) & $44.7(16.2)$ & $48.1(17.2)$ & $43.2(15.5)$ \\
\hline CAT score, mean (SD) & $19.2(6.1)$ & $21.1(6.5)$ & $18.4(5.7)$ \\
\hline Rescue medication use ${ }^{c}$, puffs/day, mean (SD) & $2.2(2.5)$ & $2.8(3.0)$ & $1.9(2.1)$ \\
\hline Rescue-free days $^{c}, \%$ (SD) & $39.4(41.6)$ & $35.6(4 I .4)$ & $41.0(41.6)$ \\
\hline
\end{tabular}

Notes: ${ }^{2}$ Number of patients with an exacerbation requiring oral or systemic corticosteroids and/or antibiotics (moderate) in 12 months prior to screening (patients with $>1$ moderate exacerbation or with a severe exacerbation [requiring hospitalization] were excluded from the study); ${ }^{\text {ban }}$ additional $4(<1 \%)$ patients with GOLD grade I (MN $\mathrm{n}=\mathrm{I}$; MT $\mathrm{n}=3$ ) were randomized; 'during the 4-week run-in period.

Abbreviations: BDI, baseline dyspnea index; CAT, COPD Assessment Test; COPD, chronic obstructive pulmonary disease; E-RS, Evaluating Respiratory Symptoms-COPD; $\mathrm{FEV}_{1}$; forced expiratory volume in I second; FVC, forced vital capacity; GOLD, Global initiative for chronic Obstructive Lung Disease; ITT, intent-to-treat; MN, maintenancenaive; MT, maintenance-treated; SD, standard deviation; SGRQ, St George's Respiratory Questionnaire.

To assess improvements from baseline with UMEC/VI, UMEC, and SAL in MN and MT patients, multidimensional plots of LS mean change from baseline in the four clinical outcomes of interest (trough $\mathrm{FEV}_{1}$ at Week 24 [upward axis], SAC-TDI focal score at Week 24 [rightward axis], rescue medication mean inhalations/day over Weeks 1-24 [downward axis], and SGRQ score at Week 24 [leftward axis]) are presented for each subgroup.

Safety endpoints were analyzed descriptively.

\section{Results}

\section{Study Population}

The ITT population included 2425 patients, of whom 749 (31\%) were MN (UMEC/VI: 250, UMEC: 250, SAL: 249) and 1676 (69\%) were MT (UMEC/VI: 562, UMEC: 554, SAL: 560). Overall, $619(83 \%) \mathrm{MN}$ patients and 1431
(85\%) MT patients completed study treatment. In the MN subgroup, $84 \%, 80 \%$, and $84 \%$ of patients receiving UMEC/VI, UMEC, and SAL completed the trial; the corresponding proportions in the MT subgroup were $90 \%$, $81 \%$, and $85 \%$. A post hoc analysis revealed that the risk of early withdrawal in the MT subgroup was lower with UMEC/VI than with UMEC (risk reduction [95\% CI]: $48 \%[28,62])$ or SAL $(36 \%[10,54])$. In the MN subgroup, the difference in risk of early withdrawal was $24 \%$ $(-15,50)$ with UMEC/VI versus UMEC and $5 \%(-47,39)$ versus SAL.

Baseline demographics and clinical characteristics for each subgroup are described in Table 1 and were well balanced between treatment arms (Supplementary Table $\underline{\mathrm{S}}$ ). Compared with the MT subgroup, the MN subgroup was slightly younger and included a greater proportion of 
females and current smokers. The MN subgroup appeared to have better lung function on average than the MT subgroup, as indicated by a higher mean $\mathrm{FEV}_{1}$ and a larger proportion of individuals who were classified as GOLD grade 2 versus 3. Furthermore, the MN subgroup had more severe symptom burden and worse health status (as indicated by higher mean CAT, E-RS, and SGRQ scores), as well as greater mean daily albuterol use than the MT subgroup. Fewer MN than MT patients had a moderate exacerbation in the previous year.

\section{Lung Function Outcomes}

In $\mathrm{MN}$ patients, mean $(95 \% \mathrm{CI})$ change from baseline in trough $\mathrm{FEV}_{1}$ at Week 24 was $44 \mathrm{~mL}(1,87)$ and $128 \mathrm{~mL}$ $(85,171)$ greater with UMEC/VI versus UMEC and SAL, respectively (Table 2; Figure 1). Mean change from baseline in trough FVC and trough IC at Week 24 were also generally greater with UMEC/VI versus UMEC and SAL in MN patients (Table 2).

In MT patients, mean $(95 \% \mathrm{CI})$ change from baseline in trough $\mathrm{FEV}_{1}$ at Week 24 was $77 \mathrm{~mL}(50,104)$ and $145 \mathrm{~mL}(118,172)$ greater with UMEC/VI versus UMEC and SAL, respectively (Table 2; Figure 1). Mean changes from baseline in trough FVC and trough IC at Week 24 were also greater with UMEC/VI versus UMEC and SAL (Table 2).

In both $\mathrm{MN}$ and MT subgroups, mean changes from baseline in trough $\mathrm{FEV}_{1}$, and trough FVC at Week 24 were greater with UMEC versus SAL (Supplementary Table S3).

\section{Symptom Severity and Health Status Outcomes}

In the MN subgroup, mean improvements from baseline in SAC-TDI focal score and E-RS total score at all time points (Figure 2A-B) and the odds of responding for either outcome (Figure 3A) were greater with UMEC/VI versus UMEC or SAL. Mean improvements in rescue medication inhalations/ day and the proportion of rescue-free days were also greater with UMEC/VI versus both monotherapies at all time points (Figure 4A-B) and over Weeks 1-24 (Table 2). A higher proportion of patients receiving UMEC/VI reported GADS to be improved by Week 24 (68\%) compared with UMEC $(65 \%)$ and SAL (63\%) (Table 2).

For SGRQ and CAT score, treatment differences favoring UMEC/VI were not consistently seen across all time points, although mean improvements from baseline in CAT score at
Week 24 were numerically greater with UMEC/VI compared with monotherapy (Figure 5A-B). The odds of responding for either outcome were similar with UMEC/VI and UMEC, but were greater with UMEC/VI versus SAL (Figure 3A).

For MT patients, mean improvements from baseline in SAC-TDI focal score and E-RS total score were greater with UMEC/VI versus UMEC or SAL at all time points (Figure $6 \mathrm{~A}-\mathrm{B})$, and the odds of responding for each outcome were greater with UMEC/VI compared with UMEC or SAL (Figure 3B). Mean improvements from baseline in the percentage of rescue-free days were greater with UMEC/VI versus monotherapy at all time points, although this was less clear for mean rescue medication inhalations/day (Figure 7A-B); mean change from baseline for both endpoints over Weeks 1-24 was greater with UMEC/VI versus UMEC or SAL (Table 2). A greater proportion of patients reported the overall severity of their COPD (GADS) improved from baseline to Week 24 with UMEC/VI (66\%) versus UMEC (60\%) and SAL (61\%) (Table 2).

Mean improvements from baseline in SGRQ and CAT scores were consistently greater with UMEC/VI over SAL, but not UMEC, at all time points (Figure 8A-B). The odds of being a responder for either SGRQ or CAT were numerically greater with UMEC/VI than with UMEC or SAL (Figure 3B).

For both subgroups, SAC-TDI scores at Week 24 were similar with UMEC and SAL; mean improvements from baseline in E-RS total score at Weeks 21-24 were slightly greater with UMEC versus SAL (Supplementary Table S3). Improvements from baseline in rescue medication use were generally similar with UMEC and SAL, although improvement from baseline in the percentage of rescue-free days was slightly larger with SAL than UMEC in the MN subgroup (Supplementary Table S3). In both subgroups, a similar proportion of patients reported improvement in the overall severity of their COPD from baseline to Week 24 with UMEC compared with SAL (Supplementary Table S3).

\section{Exacerbations and Disease Stability Outcomes}

In the $\mathrm{MN}$ subgroup, the risk of a first moderate/severe exacerbation with UMEC/VI was similar versus UMEC, with a risk reduction of $8 \%$ (HR: 0.92 ; 95\% CI: $-68,49$ ), and lower versus SAL with a risk reduction of $42 \%$ (HR: $0.58 ; 95 \%$ CI: 0,66 ). There was a reduced risk of a first CID with UMEC/VI versus UMEC for two of the three CID definitions, and versus SAL for all three definitions (Figure 9A). 


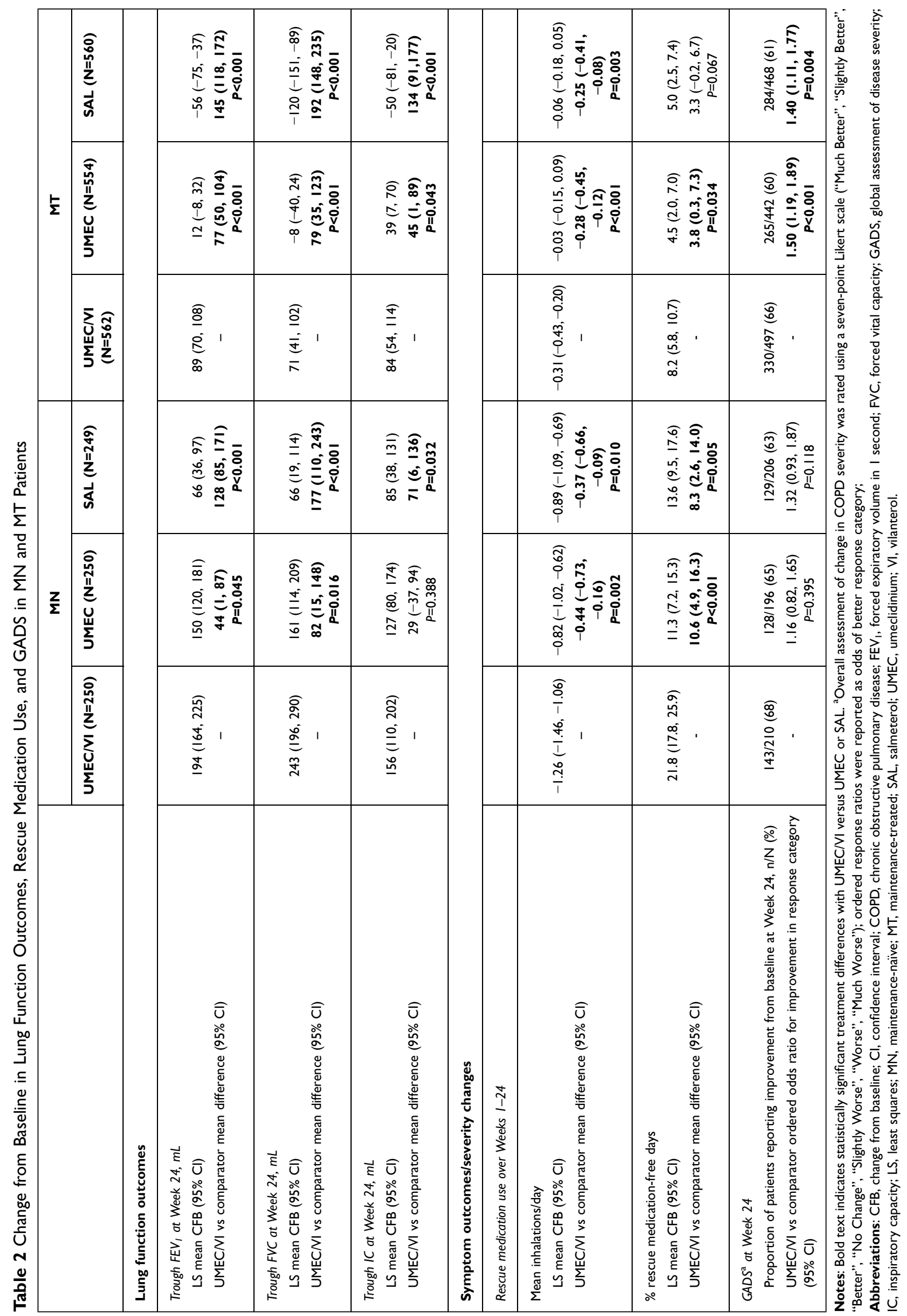


A $\mathrm{MN}$

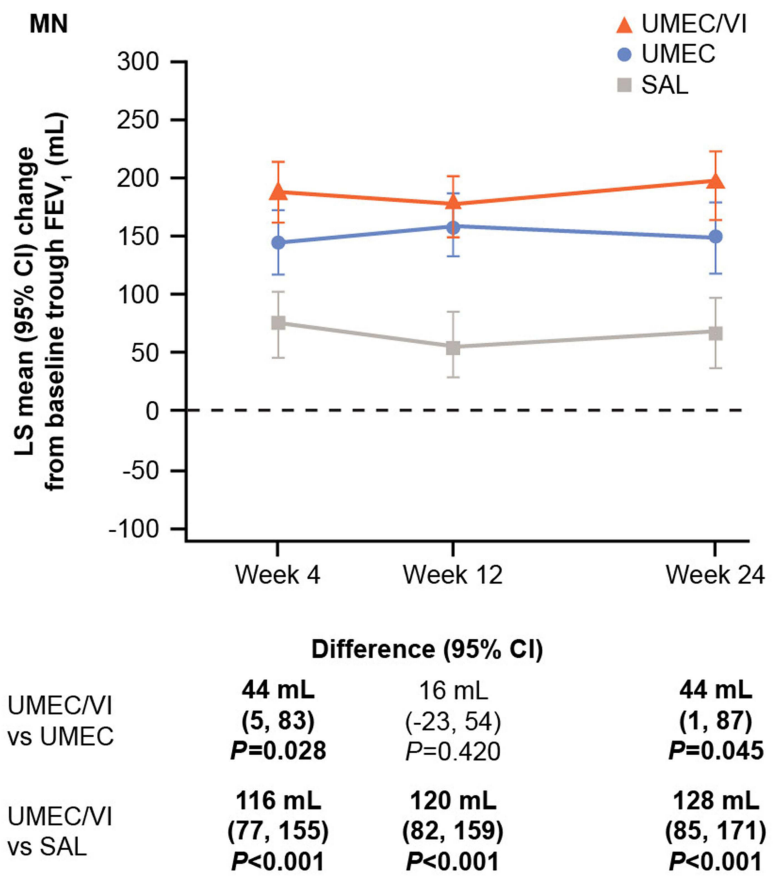

B

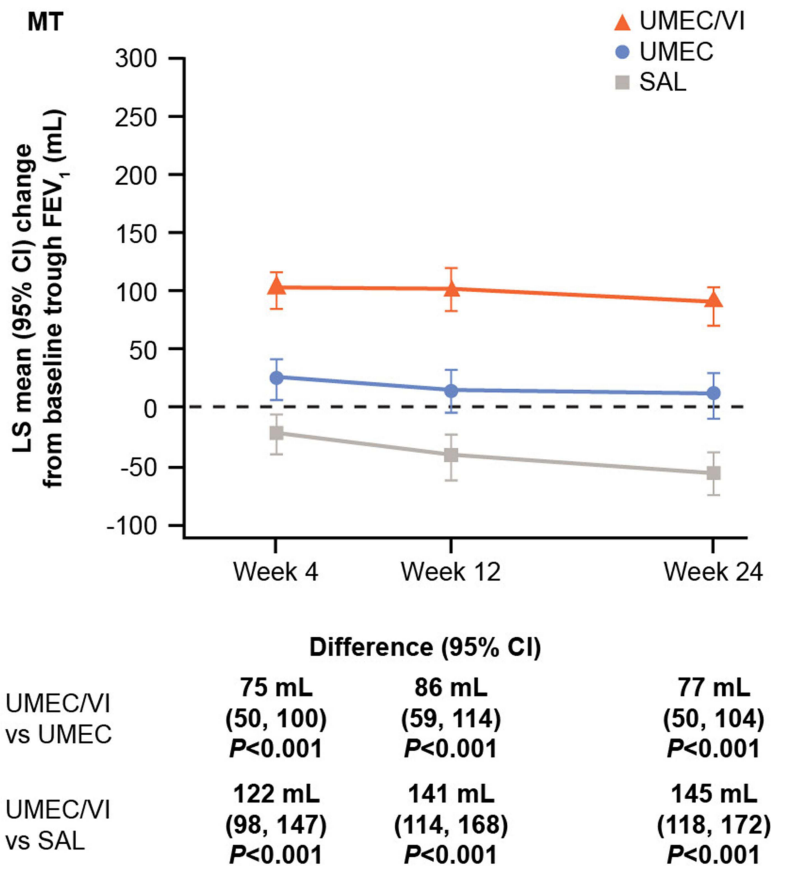

Figure I Change from baseline in trough $\mathrm{FEV}_{\text {I }}$ at Weeks 4, 12, and 24 in (A) MN and (B) MT patients.

Abbreviations: $\mathrm{Cl}$, confidence interval; $\mathrm{FEV}_{\mathrm{l}}$, forced expiratory volume in I second; LS, least squares; MN, maintenance-naïve; MT, maintenance-treated; SAL, salmeterol; UMEC, umeclidinium; VI, vilanterol.

In MT patients, the risk of a first moderate/severe exacerbation was reduced by $22 \%$ with UMEC/VI versus UMEC (HR: $0.78 ; 95 \% \mathrm{CI}:-5,42$ ) and $33 \%$ versus SAL (HR: $0.67 ; 95 \%$ CI: 11, 50). The risk of a first CID was reduced with UMEC/VI versus UMEC and versus SAL for all three CID definitions (Figure 9B).

\section{Effect of Maintenance Therapy Status on Mean Improvements from Baseline}

The overall impact of each treatment was evaluated using multidimensional plots of the four clinical outcomes of interest (trough $\mathrm{FEV}_{1}$ at Week 24 [upward axis], SAC-TDI focal score at Week 24 [rightward axis], rescue medication mean inhalations/day over Weeks 1-24 [downward axis], and SGRQ score at Week 24 [leftward axis]). For both MN (Figure 10A) and MT (Figure 10B) subgroups, greater LS mean changes from baseline were observed with UMEC/VI compared with UMEC and SAL for all outcomes except SGRQ. For both subgroups, a greater total area inside the plots was seen for UMEC/VI versus either monotherapy, indicating greater benefits across the assessed clinical outcomes. For all four endpoints, improvements from baseline were numerically greater in the MN subgroup than in the MT subgroup for all treatment arms. For improvements from baseline in trough $\mathrm{FEV}_{1}$ and rescue medication use, there was no overlap in CIs between the MN and MT subgroups for either outcome in any treatment arm, suggesting consistently greater improvements for $\mathrm{MN}$ versus MT patients irrespective of treatment (Figure 10). A similar pattern of improvements from baseline was observed when these outcomes were assessed at Week 4 for MN and MT patients (Supplementary Figure S1). Absolute mean values at Week 24 (or over Weeks 1-24 for rescue medication use) for all four measures were similar between the MN and MT subgroups (Supplementary Figure S2).

\section{Safety}

The incidence of patients reporting on-treatment AEs and SAEs was similar in all treatment arms in both subgroups (Table 3). In the MN subgroup, no SAEs were considered drug-related and no fatal SAEs were reported. In the MT subgroup, eight fatal SAEs were reported (four each in the UMEC/VI and UMEC treatment arms); however, no fatal or non-fatal SAEs were considered related to the study medication. As expected based on the known safety profile of long-acting bronchodilators, and consistent with the ITT population, ${ }^{18}$ the most common $\mathrm{AE}$ was nasopharyngitis in both subgroups (Table 3 ).

\section{Discussion}

This pre-specified analysis of the EMAX trial by patient maintenance therapy status prior to randomization found larger 
A SAC-TDI

$\triangle \mathrm{UMEC} / \mathrm{VI} \bullet \mathrm{UMEC} \backsim \mathrm{SAL}$

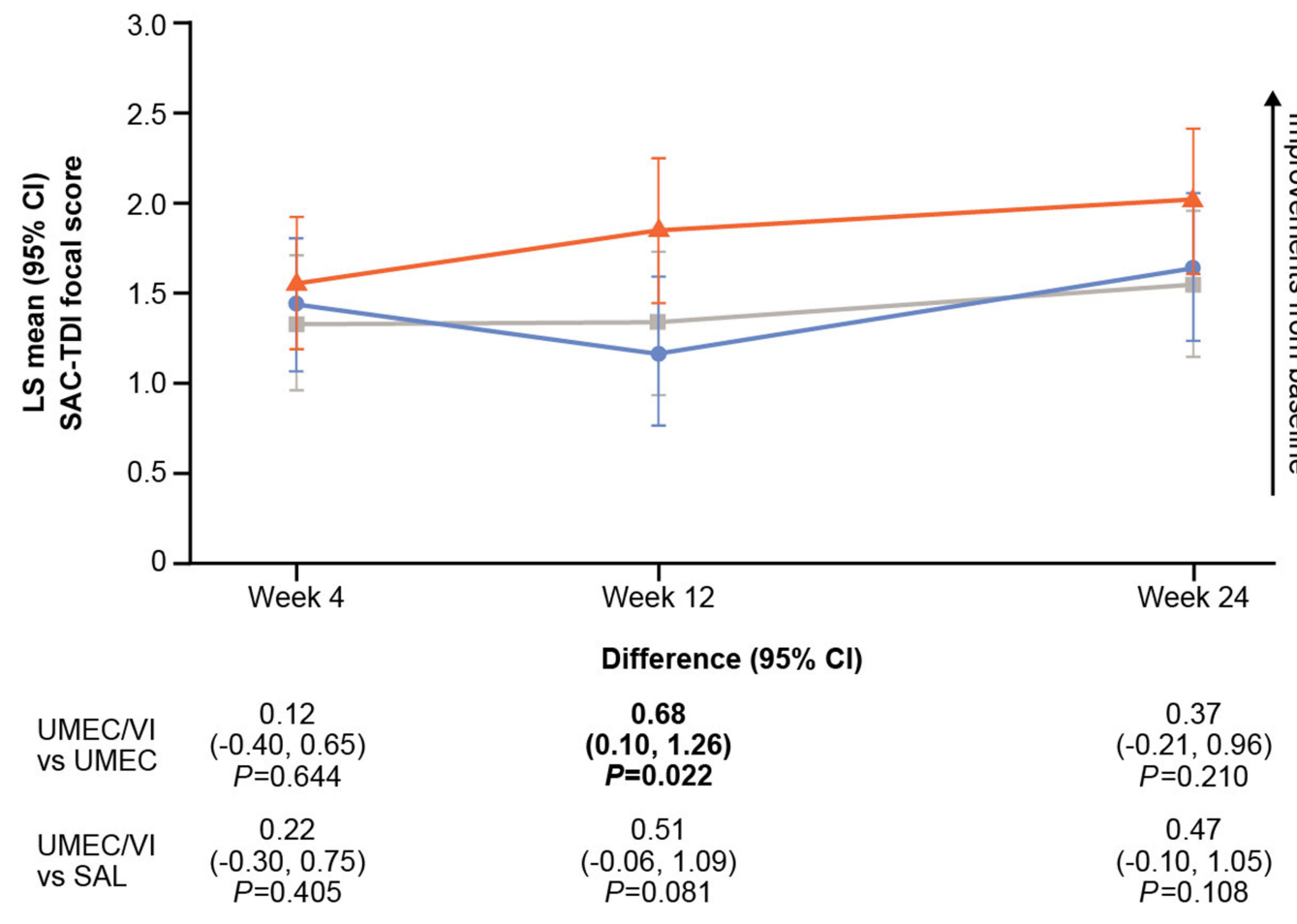

B E-RS $\triangle \mathrm{UMEC} / \mathrm{VI} \bullet \mathrm{UMEC} \backsim \mathrm{SAL}$

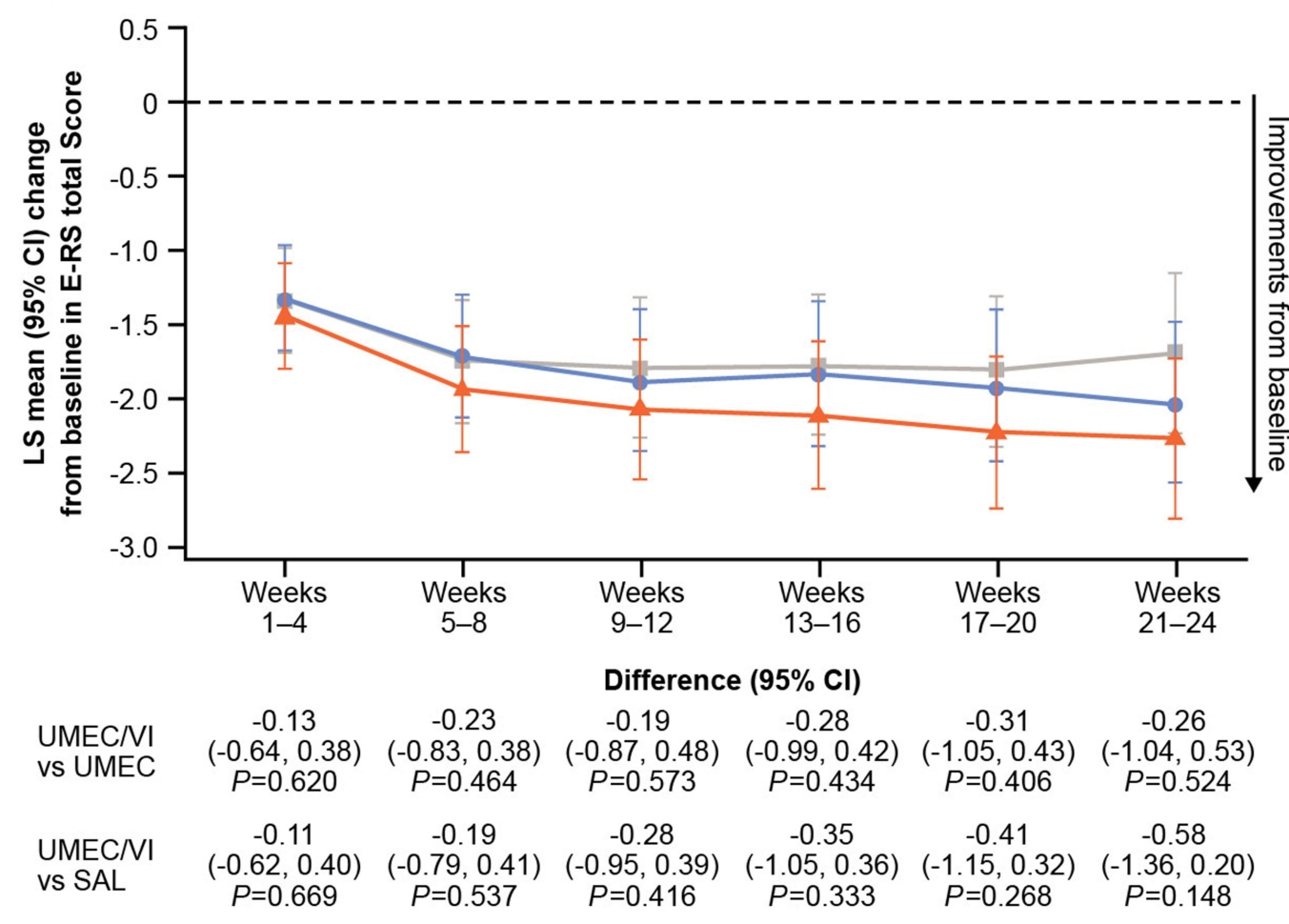

Figure 2 MN patients: (A) SAC-TDI focal score and (B) change from baseline in E-RS total score.

Abbreviations: $\mathrm{Cl}$, confidence interval; COPD, chronic obstructive pulmonary disease; E-RS, Evaluating Respiratory Symptoms-COPD; LS, least squares; MN, maintenancenaïv; MT, maintenance-treated; SAC-TDI, self-administered computerized Transition Dyspnea Index; SAL, salmeterol; UMEC, umeclidinium; VI, vilanterol. 


\section{A MN}

\begin{tabular}{lcccccc}
\hline Outcome & Treatment & $\begin{array}{c}\text { Responders } \\
\text { n/N (\%) }\end{array}$ & $\begin{array}{c}\text { UMEC/VI vs } \\
\text { comparator } \\
\text { OR (95\% CI) }\end{array}$ & $P$
\end{tabular}

\section{B MT}

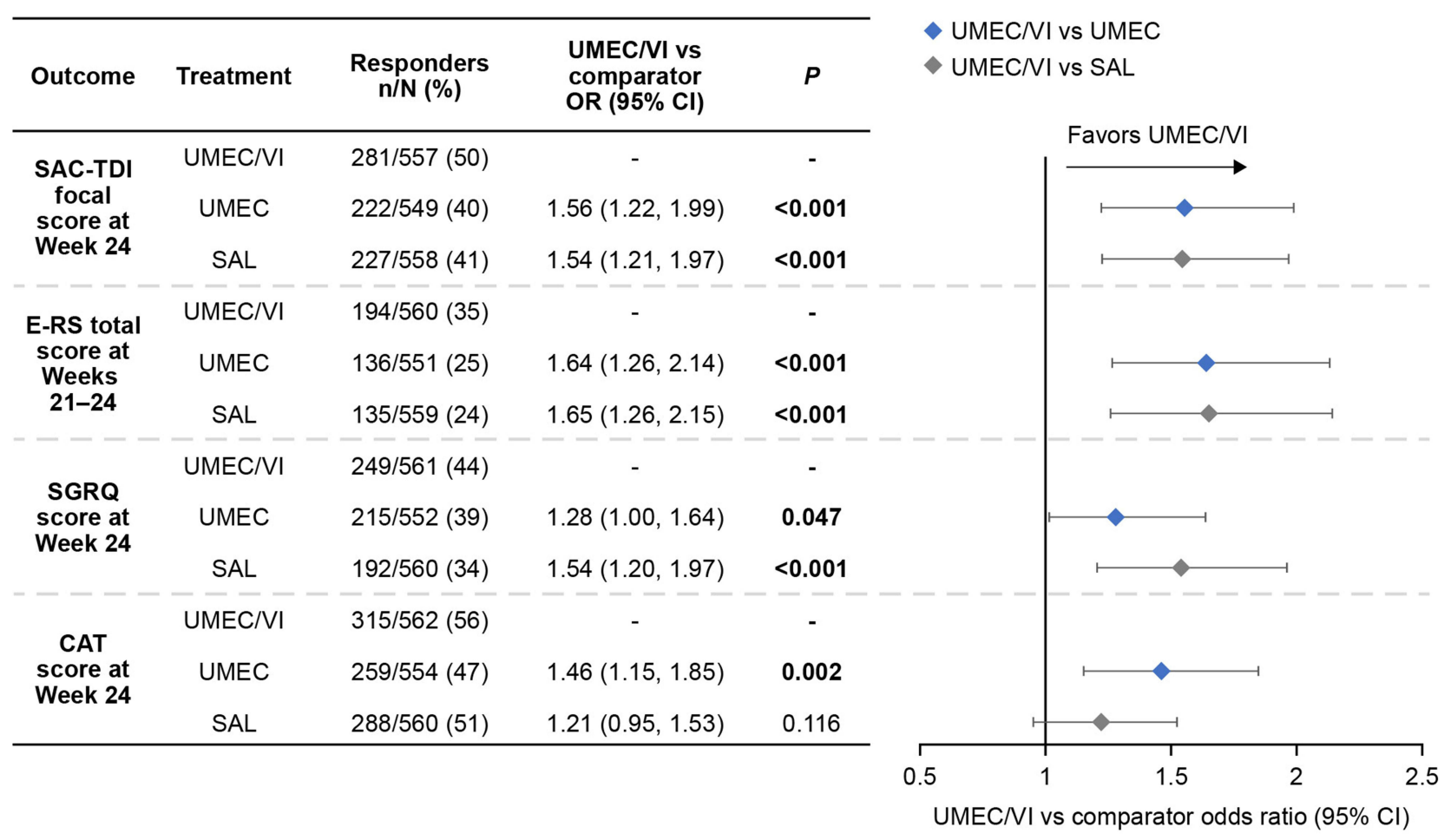

Figure 3 Proportion of responders for symptoms (SAC-TDI focal score, E-RS total score) and health status outcomes (SGRQ, and CAT) in (A) MN and (B) MT patients. Abbreviations: CAT, COPD Assessment Test; Cl, confidence interval; COPD, chronic obstructive pulmonary disease; E-RS, Evaluating Respiratory Symptoms-COPD; MN, maintenance-naïv; MT, maintenance-treated; $\mathrm{n} / \mathrm{N}$ number of responders/number of patients with analyzable data; SAC-TDI, self-administered computerized Transition Dyspnea Index; SAL, salmeterol; SGRQ, St George's Respiratory Questionnaire; UMEC, umeclidinium; VI, vilanterol. 
A Rescue medication-free days

$\triangle \mathrm{UMEC} / \mathrm{VI} \quad-\mathrm{UMEC} \backsim \mathrm{SAL}$

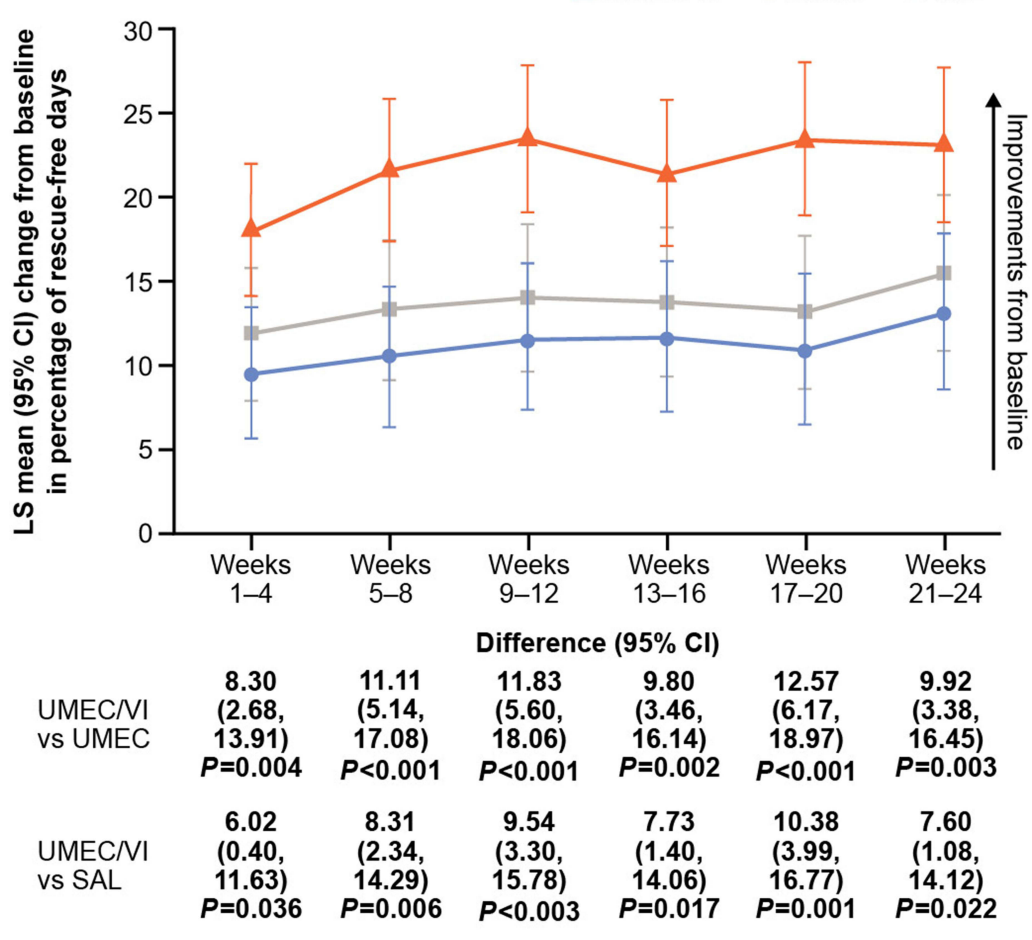

B Rescue medication inhalations/day

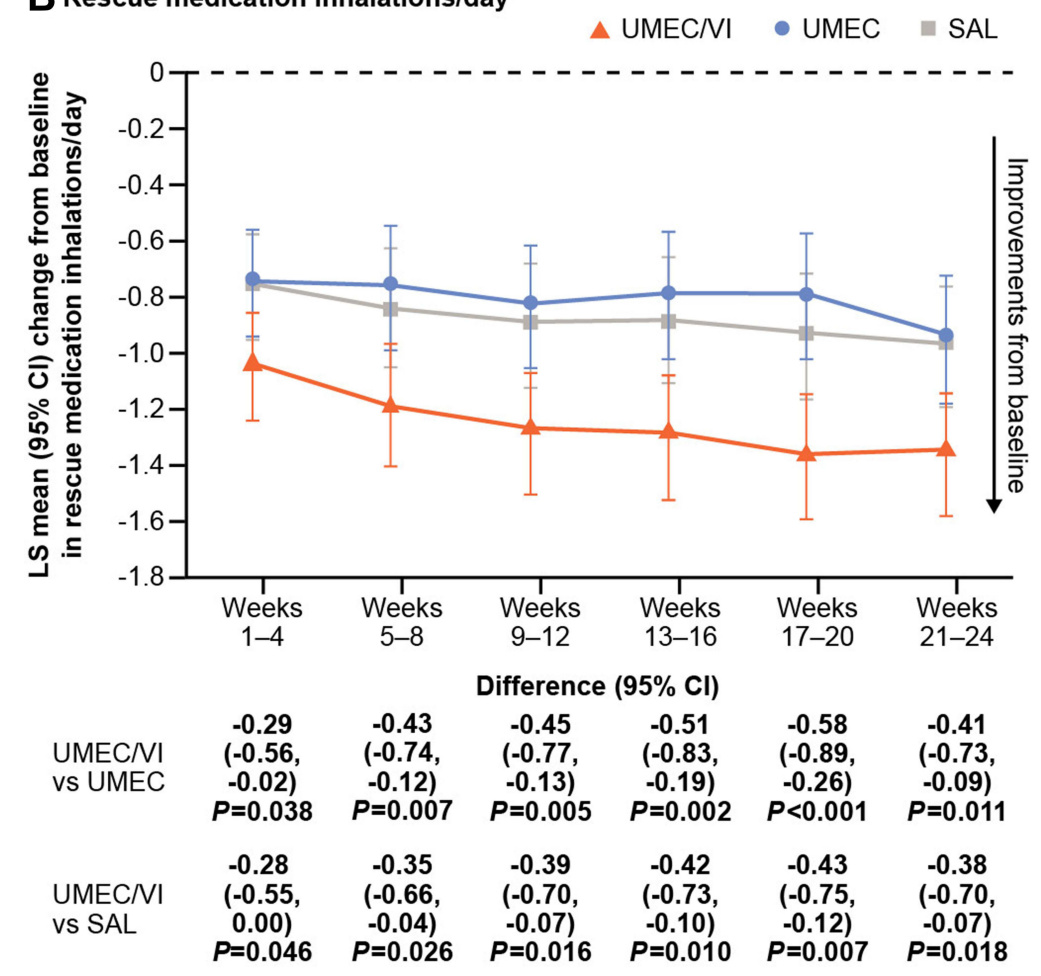

Figure $4 \mathrm{MN}$ patients: change from baseline in (A) percentage of rescue-free days and (B) rescue medication inhalations/day.

Abbreviations: $\mathrm{Cl}$, confidence interval; LS, least squares; MN, maintenance-naïve; MT, maintenance-treated; SAL, salmeterol; UMEC, umeclidinium; VI, vilanterol. 


\section{A SGRQ}

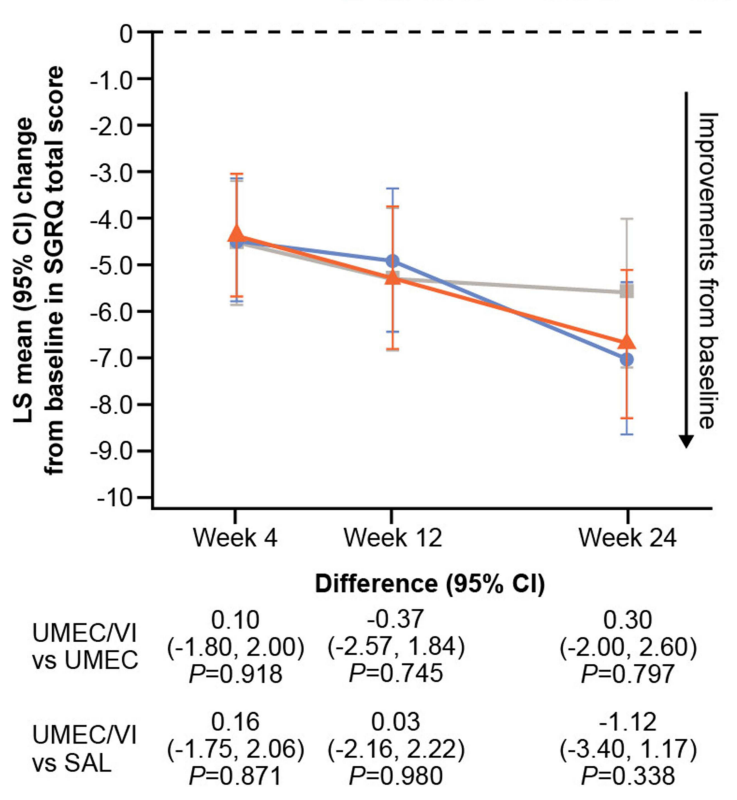

B CAT

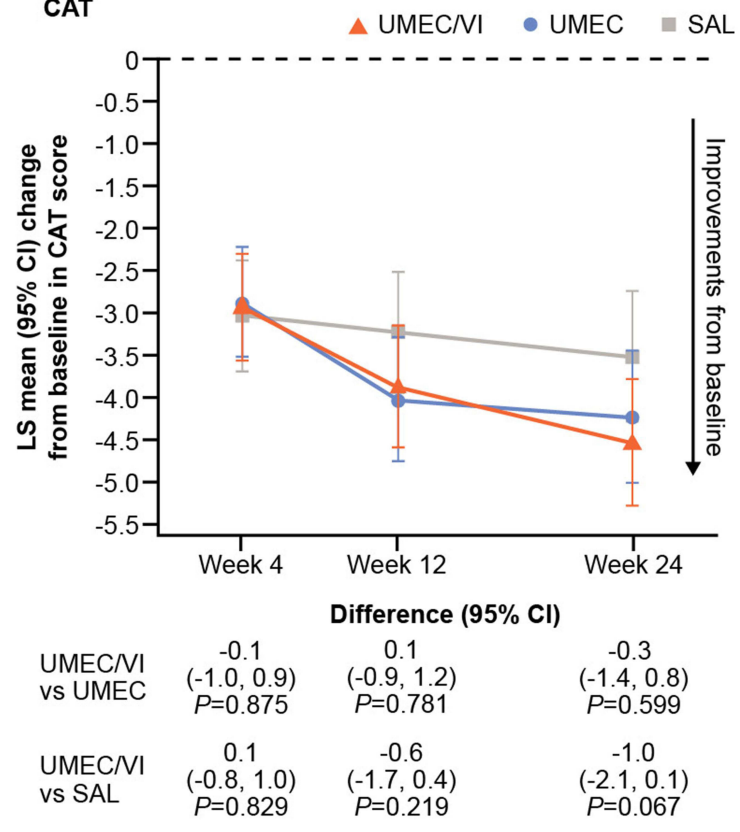

Figure 5 MN patients: change from baseline in (A) SGRQ total score and (B) CAT score.

Abbreviations: CAT, COPD Assessment Test; $\mathrm{Cl}$, confidence interval; COPD, chronic obstructive pulmonary disease; LS, least squares; $M N$, maintenance-naïv; MT, maintenance-treated; SAL, salmeterol; SGRQ, St George's Respiratory Questionnaire; UMEC, umeclidinium; VI, vilanterol.

improvements in lung function and reductions in rescue medication use, which may be an indirect marker of reduced symptom burden, in patients receiving UMEC/VI compared with either monotherapy from Week 4 to Week 24, in both the MN and MT subgroups. Rescue medication benefits of
A SAC-TDI

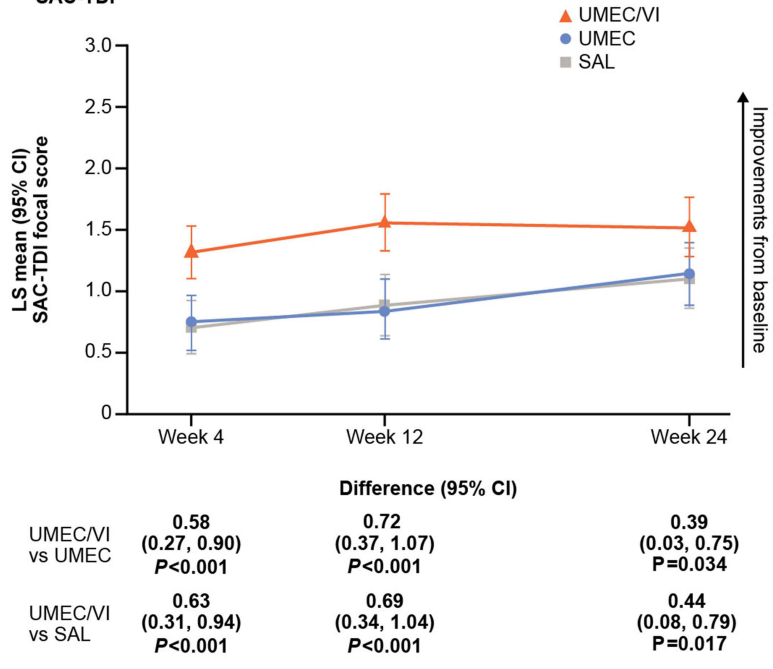

B E-RS

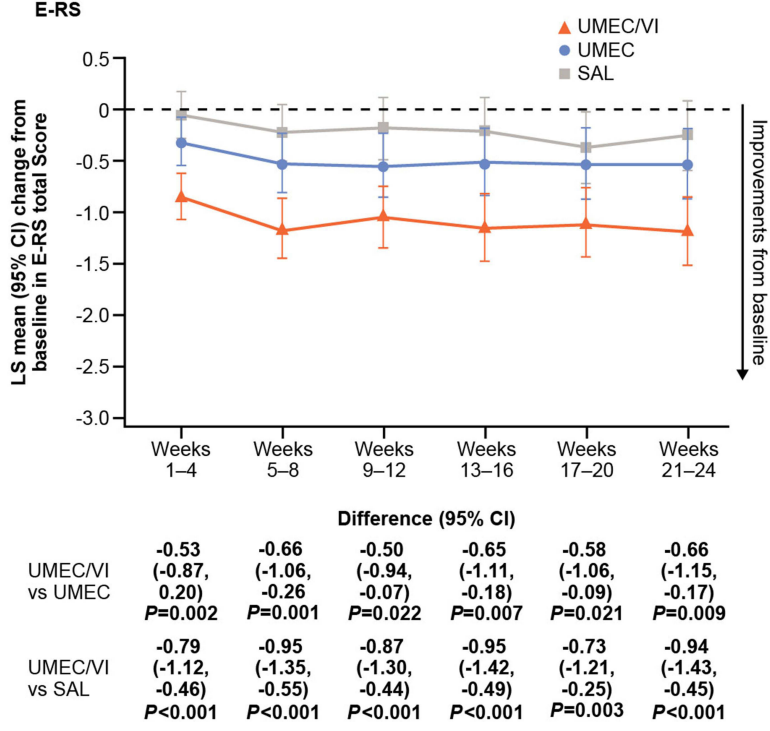

Figure 6 MT patients: (A) SAC-TDI focal score and (B) change from baseline in E-RS total score.

Abbreviations: $\mathrm{Cl}$, confidence interval; COPD, chronic obstructive pulmonary disease; E-RS, Evaluating Respiratory Symptoms-COPD; LS, least squares; MN, maintenance-naïve; MT, maintenance-treated; SAC-TDI, self-administered computerized Transition Dyspnea Index; SAL, salmeterol; UMEC, umeclidinium; VI, vilanterol.

UMEC/VI included both a reduced number of uses per day and increased rescue-free days versus UMEC and SAL, suggesting that patients' symptoms improved as they were less dependent on their rescue inhaler. ${ }^{19}$ For SAC-TDI and E-RS at Week 24, UMEC/VI also showed numerically larger improvements from baseline versus monotherapy. In addition, risk of exacerbations and risk of CID were generally reduced with UMEC/VI versus monotherapy for both subgroups. Patients in both subgroups also showed generally greater improvements with UMEC versus SAL for lung function (trough $\mathrm{FEV}_{1}$, 

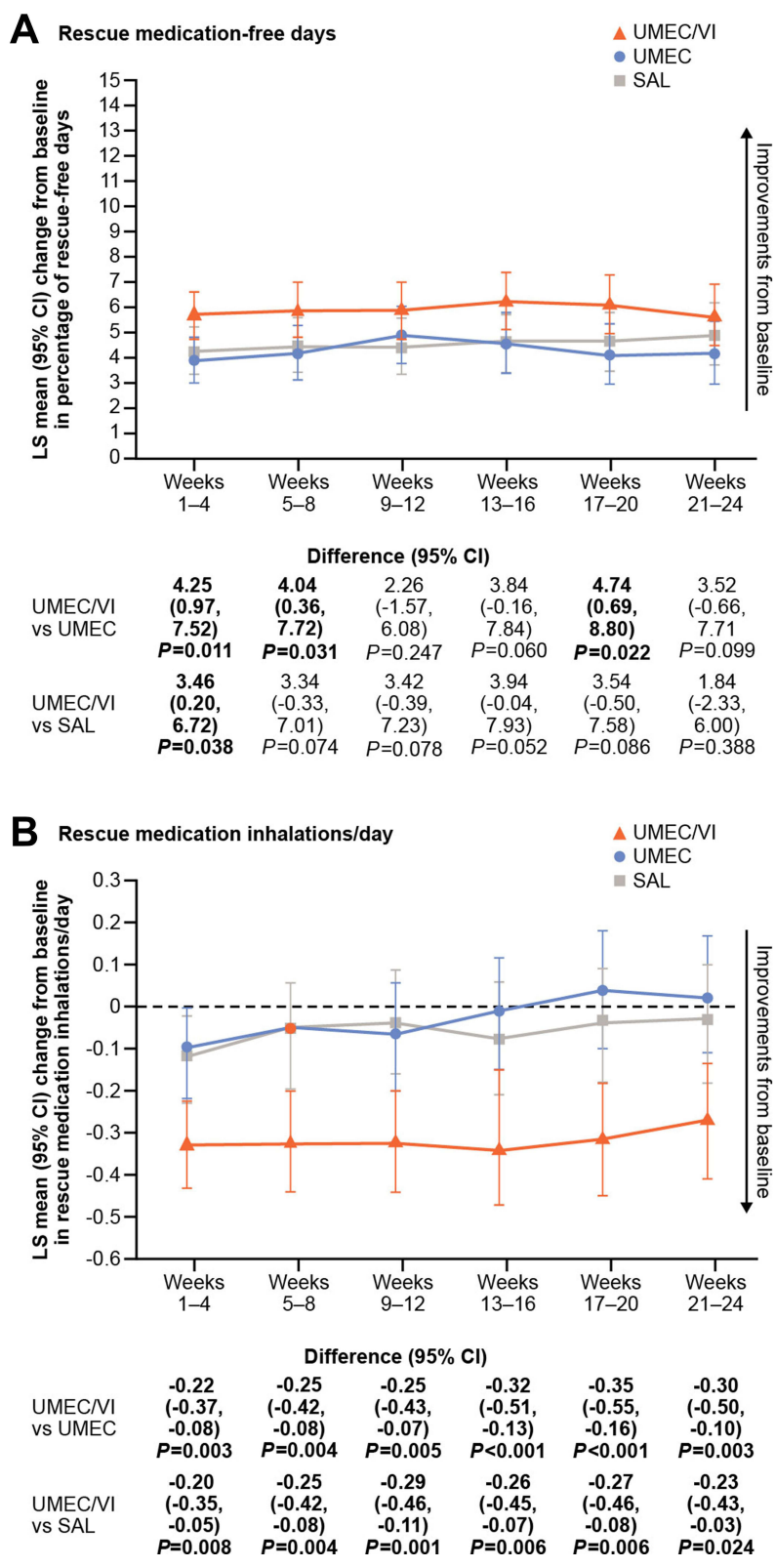

Figure 7 MT patients: change from baseline in (A) percentage of rescue-free days and $(\mathbf{B})$ rescue medication inhalations/day.

Abbreviations: $\mathrm{Cl}$, confidence interval; $\mathrm{LS}$, least squares; $\mathrm{MN}$, maintenance-naïve; MT, maintenance-treated; SAL, salmeterol; UMEC, umeclidinium; VI, vilanterol.

trough FVC, and trough IC), but not for symptoms outcomes (SAC-TDI, E-RS, and rescue medication use) or COPD severity (GADS). All treatments were equally well tolerated in both subgroups. Taken together, these data support an incremental efficacy benefit on lung function, rescue medication use and greater disease stability when using dual bronchodilator treatment as initial maintenance therapy.

In the GOLD strategy report, maintenance bronchodilator therapy is recommended for patients with symptomatic COPD, ${ }^{12}$ yet $31 \%$ of patients in this study were MN. This is

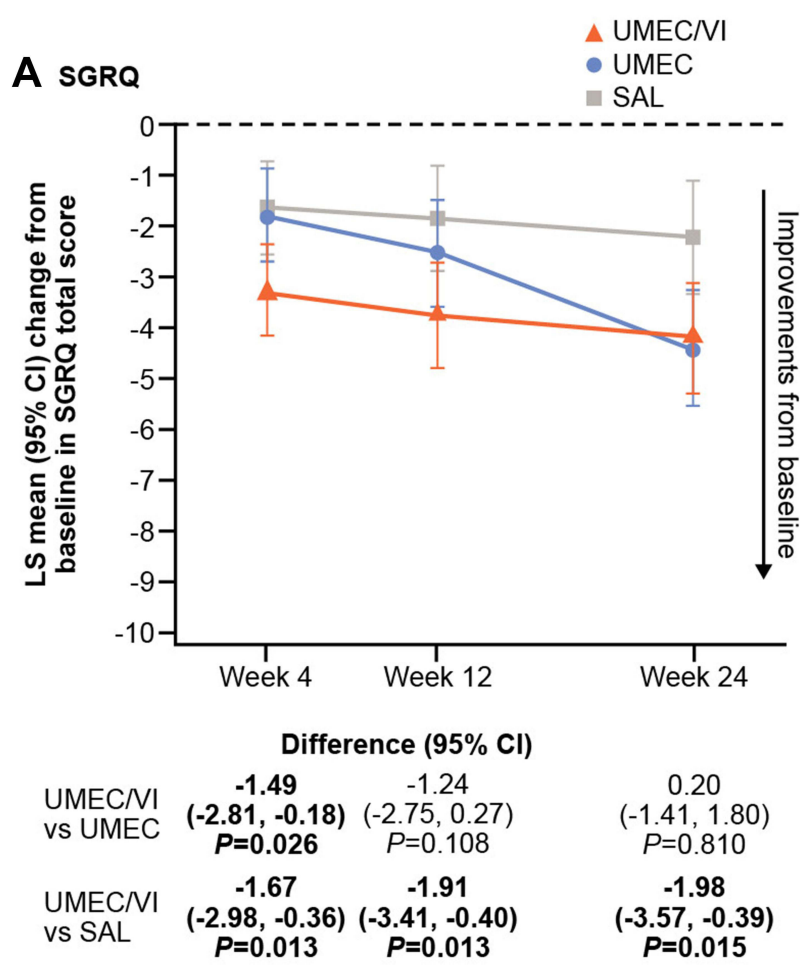

B CAT

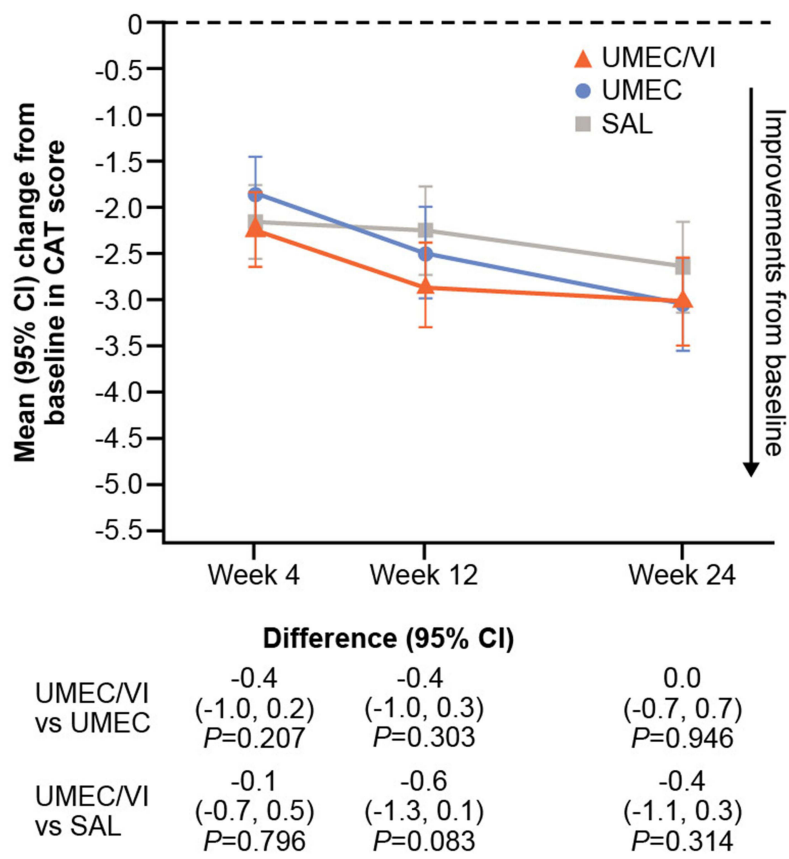

Figure 8 MT patients: change from baseline in (A) SGRQ total score and (B) CAT score. Abbreviations: CAT, COPD Assessment Test; Cl, confidence interval; COPD, chronic obstructive pulmonary disease; LS, least squares; MN, maintenance-naïve; MT, maintenance-treated; SAL, salmeterol; SGRQ, St George's Respiratory Questionnaire; UMEC, umeclidinium; VI, vilanterol.

consistent with prior estimates of the proportion of patients with COPD who do not receive any maintenance treatment despite being symptomatic. ${ }^{14}$ The lack of previous 


\begin{tabular}{|c|c|c|c|c|}
\hline \multicolumn{5}{|l|}{ MN } \\
\hline Treatment & $\begin{array}{c}\text { Incidence of CID } \\
n / N^{a}(\%)\end{array}$ & $\begin{array}{c}\text { Probability of } \\
\text { event, \% ( } 95 \% \mathrm{Cl})\end{array}$ & $\begin{array}{l}\text { UMEC/VI vs } \\
\text { comparator } \\
\text { HR ( } 95 \% \text { Cl) }\end{array}$ & $P$ \\
\hline \multicolumn{5}{|c|}{ Composite CID definitions } \\
\hline \multicolumn{5}{|c|}{ Exacerbation $^{\mathrm{b}}, \mathrm{FEV}_{1}, \mathrm{SGRQ}$} \\
\hline UMEC/VI & $112 / 239(47)$ & $46.1(39.8,52.9)$ & & \\
\hline UMEC & $99 / 240(41)$ & $43.6(37.2,50.5)$ & $1.16(0.88,1.52)$ & 0.292 \\
\hline SAL & $137 / 235(58)$ & $57.9(51.3,64.6)$ & $0.78(0.60,1.00)$ & 0.048 \\
\hline \multicolumn{5}{|c|}{ Exacerbation $^{\mathrm{b}}, \mathrm{FEV}_{1}, \mathrm{CAT}$} \\
\hline UMEC/VI & $104 / 239(44)$ & $40.8(34.7,47.4)$ & & \\
\hline UMEC & $109 / 240(45)$ & $47.4(40.8,54.4)$ & $0.90(0.69,1.18)$ & 0.454 \\
\hline SAL & $128 / 235(54)$ & $54.1(47.7,60.7)$ & $0.70(0.54,0.90)$ & 0.006 \\
\hline \multicolumn{5}{|c|}{ Exacerbation $^{\mathrm{b}}, \mathrm{CAT}, \mathrm{SGRQ}, \mathrm{SAC}-\mathrm{TDI}$} \\
\hline UMEC/VI & $143 / 241(59)$ & $57.7(51.3,64.3)$ & & \\
\hline UMEC & $158 / 244(65)$ & $66.0(59.7,72.3)$ & $0.84(0.67,1.06)$ & 0.144 \\
\hline SAL & $166 / 242(69)$ & $68.6(62.3,74.8)$ & $0.80(0.64,1.00)$ & 0.052 \\
\hline
\end{tabular}

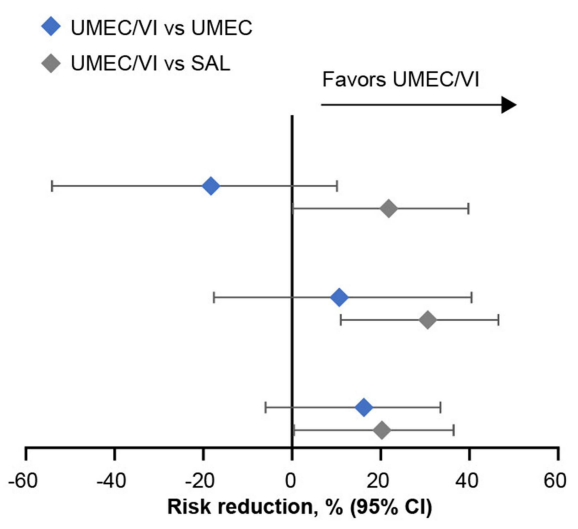

B

\begin{tabular}{|c|c|c|c|c|}
\hline Treatment & $\begin{array}{c}\text { Incidence of CID } \\
\mathrm{n} / \mathrm{N}^{2}(\%)\end{array}$ & $\begin{array}{c}\text { Probability of } \\
\text { event, \% (95\% Cl) }\end{array}$ & $\begin{array}{l}\text { UMEC/VI vs } \\
\text { comparator } \\
\text { HR }(95 \% \text { CI) }\end{array}$ & $P$ \\
\hline \multicolumn{5}{|c|}{ Composite CID definitions } \\
\hline \multicolumn{5}{|c|}{ Exacerbation $^{\mathrm{b}}, \mathrm{FEV}_{1}, \mathrm{SGRQ}$} \\
\hline $\begin{array}{l}\text { UMEC/NI } \\
\text { UMEC } \\
\text { SAL }\end{array}$ & $\begin{array}{l}318 / 541(59) \\
340 / 501(68) \\
408 / 523(78)\end{array}$ & $\begin{array}{l}55.7(51.4,60.0) \\
68.0(63.6,72.2) \\
74.8(70.9,78.5)\end{array}$ & $\begin{array}{l}0.74(0.64,0.86) \\
0.59(0.51,0.68)\end{array}$ & $\begin{array}{l}<0.001 \\
<0.001\end{array}$ \\
\hline \multicolumn{5}{|c|}{ Exacerbation $^{\mathrm{b}}, \mathrm{FEV}_{1}, \mathrm{CAT}$} \\
\hline $\begin{array}{l}\text { UMEC/VI } \\
\text { UMEC } \\
\text { SAL }\end{array}$ & $\begin{array}{l}298 / 542(55) \\
340 / 503(68) \\
402 / 523(77)\end{array}$ & $\begin{array}{l}52.9(48.6,57.3) \\
66.4(62.1,70.7) \\
72.8(68.9,76.7)\end{array}$ & $\begin{array}{l}0.70(0.60,0.82) \\
0.56(0.48,0.65)\end{array}$ & $\begin{array}{l}<0.001 \\
<0.001\end{array}$ \\
\hline \multicolumn{5}{|c|}{ Exacerbation', CAT, SGRQ, SAC-TDI } \\
\hline $\begin{array}{l}\text { UMEC/NI } \\
\text { UMEC } \\
\text { SAL }\end{array}$ & $\begin{array}{l}357 / 550(65) \\
366 / 517(71) \\
412 / 533(77)\end{array}$ & $\begin{array}{l}62.8(58.7,66.9) \\
711.5(67.4,75.5) \\
75.5(71.7,79.2)\end{array}$ & $\begin{array}{l}0.84(0.73,0.97) \\
0.72(0.63,0.83)\end{array}$ & $\begin{array}{r}0.021 \\
<0.001\end{array}$ \\
\hline
\end{tabular}

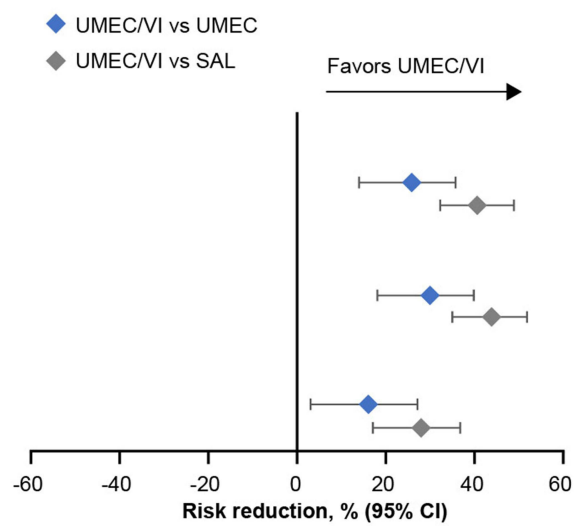

Figure 9 Risk of a first clinically important deterioration in (A) $M N$ and (B) $M T$ patients. ${ }^{a} / \mathrm{N}$, number of patients with an event/number of patients with at least I post baseline assessment (not including exacerbations) for at least one of the individual components or patients who had an exacerbation; ${ }^{\mathrm{b}}$ moderate/severe exacerbation. Abbreviations: CAT, COPD Assessment Test; $\mathrm{Cl}$, confidence interval; $\mathrm{CID}$, clinically important deterioration; COPD, chronic obstructive pulmonary disease; FEV , trough forced expiratory volume in I s; HR, hazard ratio; MN, maintenance-naïve; MT, maintenance-treated; SAC-TDI, self-administered computerized Transition Dyspnea Index; SAL, salmeterol; SGRQ, St George's Respiratory Questionnaire; UMEC, umeclidinium; VI, vilanterol.

maintenance treatment suggests that the symptoms of these patients had been neglected and not treated appropriately, as these patients had been diagnosed with COPD for the same length of time as the MT patients, and had similar CAT scores. One potential reason for this could be that patients do not seek appropriate assessment and maintenance treatment due to a disparity between patient perceived and actual COPD severity. ${ }^{5}$ Furthermore, a greater proportion of MN than MT patients were current smokers; in the former group, it is possible that COPD symptoms such as dyspnea have been misattributed to smoking, further contributing to underdiagnosis and undertreatment. $^{20,21}$ This highlights the importance of thorough assessment and treatment (including smoking cessation) in $\mathrm{MN}$ patients with COPD symptoms, to prevent further deterioration. $^{12}$

A secondary objective of this analysis of the EMAX trial was to explore whether MN patients demonstrated greater improvements from baseline with dual- or mono- bronchodilator therapy compared with MT patients. There was a consistent trend for greater mean improvements from baseline in MN versus MT patients across all three treatment regimens for $\mathrm{FEV}_{1}$, SAC-TDI, rescue medication use, and SGRQ. This suggests that MN patients, who were receiving no maintenance treatment at the start of the trial, gained greater benefit from bronchodilator therapy than MT patients, who were already receiving bronchodilator therapy. $\mathrm{MN}$ patients had a greater mean rescue medication use at baseline compared with the MT subgroup, indicating that these patients were dependent on short-acting bronchodilators to control their COPD symptoms in the absence of adequate maintenance treatment. $^{22,23}$ Accordingly, the MN subgroup had more severe symptom burden and worse health status at baseline (as indicated by E-RS, CAT, and SGRQ scores), but both subgroups had a similar mean lung function, symptoms, and health status at the end of the study. These numerically larger mean improvements from baseline in the MN versus MT subgroup suggest a significant unmet need for effective maintenance 


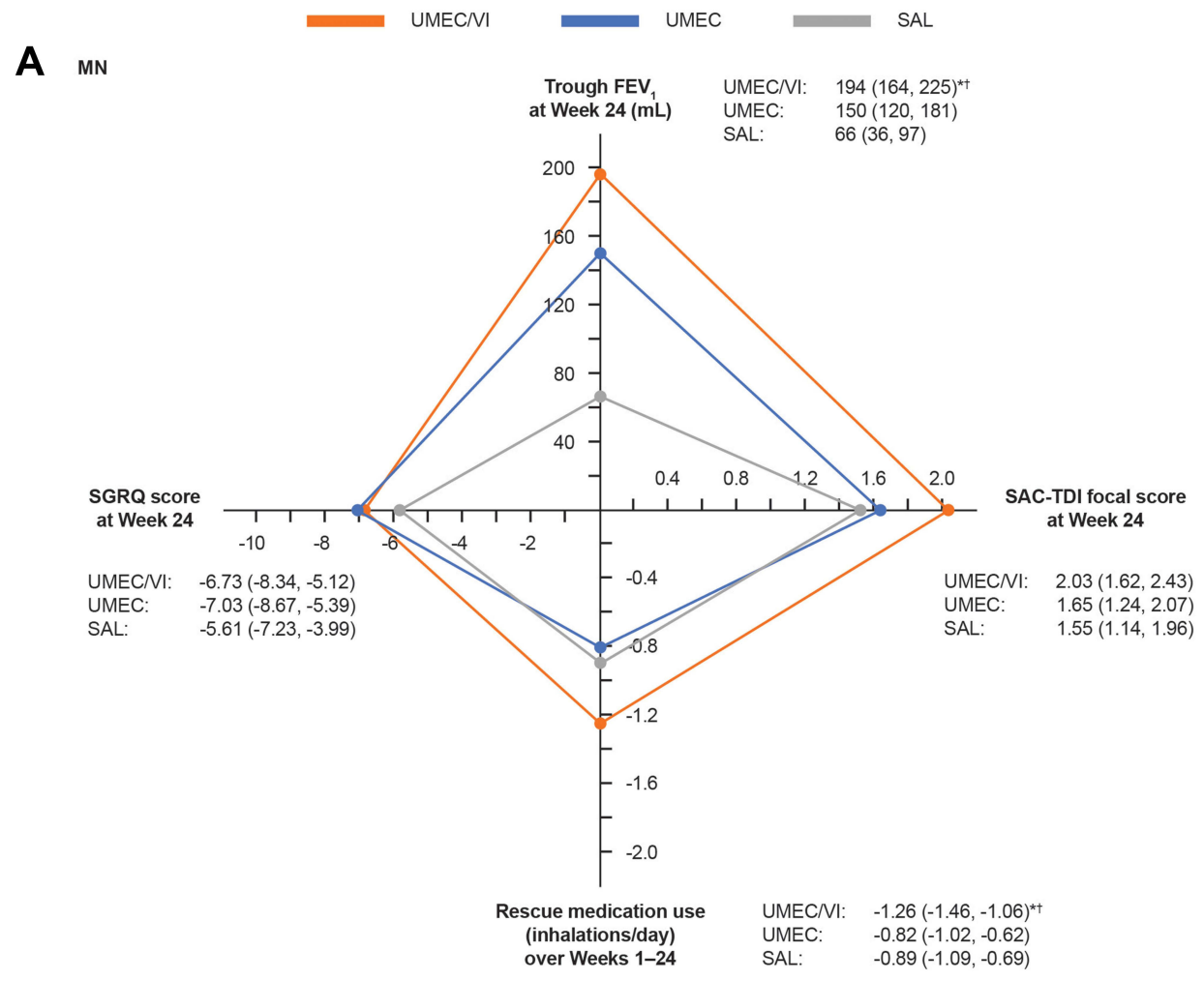

B мт

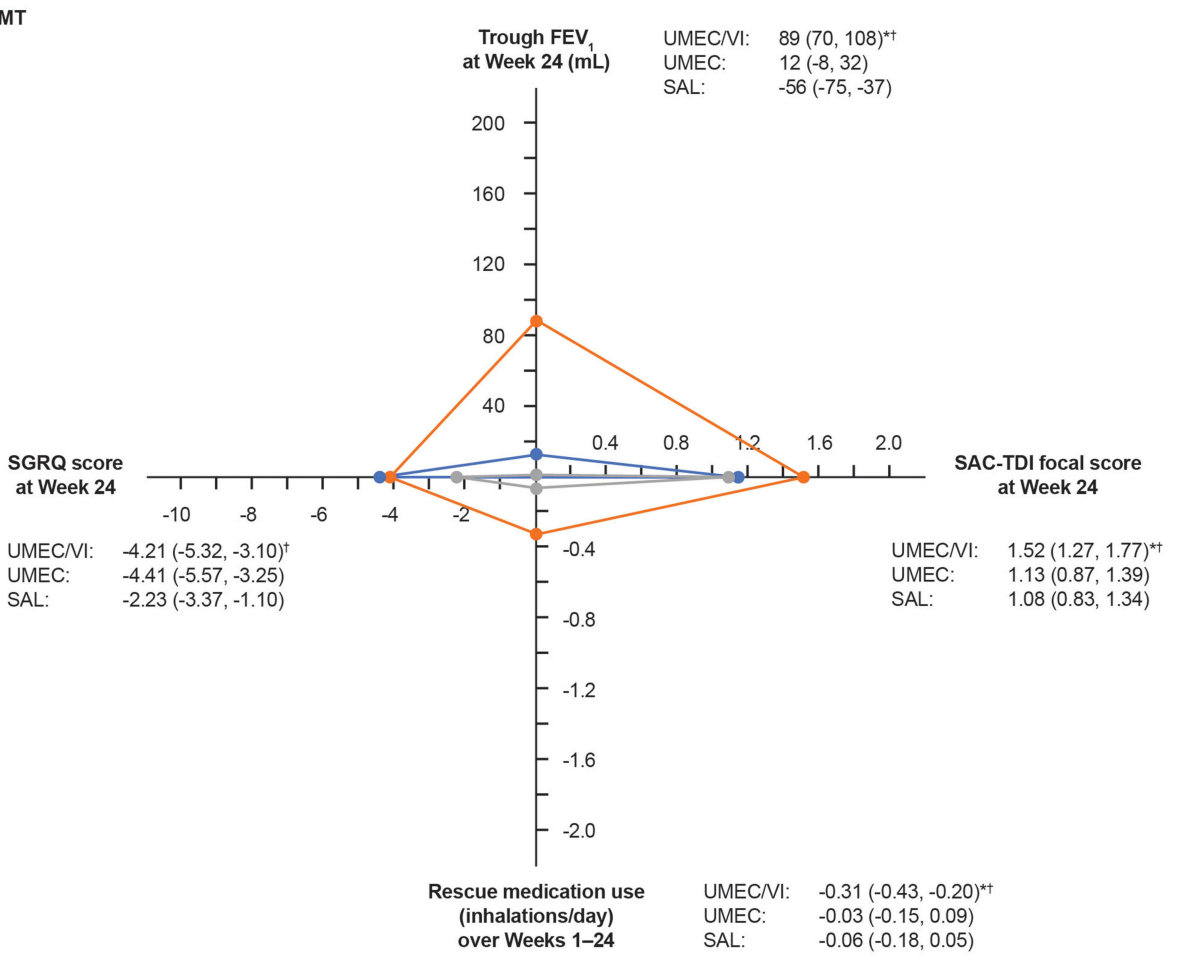

Figure 10 LS mean change from baseline in trough FEV at Week 24, SAC-TDI focal score at Week 24, rescue medication inhalations/day over Weeks I-24, and SGRQ score at Week 24 with UMEC/VI, UMEC, and SAL in (A) MN and (B) MT patients. All values are LS mean $(95 \% \mathrm{Cl})$. Negative changes from baseline are not shown, so a change from baseline in trough $\mathrm{FEV}_{1}$ at Week 24 of $-56 \mathrm{~mL}$ with SAL in the MT subgroup is presented as zero. ${ }^{* P}<0.05$ vs UMEC and ${ }^{\dagger}$ vs SAL.

Abbreviations: $\mathrm{Cl}$, confidence interval; $\mathrm{FEV}$, forced expiratory volume in I second; LS, least squares; MN, maintenance-naiive; MT, maintenance-treated; SAC-TDI, selfadministered computerized Transition Dyspnea Index; SAL, salmeterol; SGRQ, St George's Respiratory Questionnaire; UMEC, umeclidinium; VI, vilanterol. 
Table 3 Adverse Events

\begin{tabular}{|c|c|c|c|c|c|c|c|c|}
\hline & \multicolumn{4}{|c|}{ MN } & \multicolumn{4}{|c|}{ MT } \\
\hline & $\begin{array}{l}\text { UMEC/VI } \\
(\mathrm{N}=250)\end{array}$ & $\begin{array}{l}\text { UMEC } \\
(N=250)\end{array}$ & $\begin{array}{c}\text { SAL } \\
(\mathrm{N}=249)\end{array}$ & $\begin{array}{c}\text { Total } \\
(\mathrm{N}=749)\end{array}$ & $\begin{array}{l}\text { UMEC/VI } \\
(\mathrm{N}=562)\end{array}$ & $\begin{array}{l}\text { UMEC } \\
(N=554)\end{array}$ & $\begin{array}{c}\text { SAL } \\
(N=560)\end{array}$ & $\begin{array}{c}\text { Total } \\
(\mathrm{N}=1676)\end{array}$ \\
\hline \multicolumn{9}{|l|}{ AE, n (\%) } \\
\hline $\mathrm{AE}$ & $94(38)$ & $96(38)$ & $101(4 I)$ & 291 (39) & 221 (39) & $220(40)$ & $213(38)$ & 654 (39) \\
\hline Drug-related $\mathrm{AE}$ & $9(4)$ & $12(5)$ & $12(5)$ & $33(4)$ & $20(4)$ & $25(5)$ & $15(3)$ & $60(4)$ \\
\hline $\begin{array}{l}\text { AE leading to study } \\
\text { withdrawal }\end{array}$ & II (4) & $10(4)$ & $9(4)$ & $30(4)$ & $21(4)$ & $26(5)$ & $17(3)$ & $64(4)$ \\
\hline \multicolumn{9}{|l|}{ SAE, n (\%) } \\
\hline Non-fatal SAE & $12(5)$ & $15(6)$ & $13(5)$ & $40(5)$ & $34(6)$ & $16(3)$ & $25(4)$ & $75(4)$ \\
\hline Fatal $S A E^{a}$ & 0 & 0 & 0 & 0 & $4(<1)$ & $4(<1)$ & 0 & $8(<1)$ \\
\hline Drug-related SAE & 0 & 0 & 0 & 0 & 0 & 0 & 0 & 0 \\
\hline \multicolumn{9}{|c|}{ AEs occurring in $>\mathbf{2} \%$ of patients on any treatment, $n(\%)$} \\
\hline Nasopharyngitis & $14(6)$ & $15(6)$ & $19(8)$ & $48(6)$ & $54(10)$ & $72(13)$ & $65(12)$ & $191(11)$ \\
\hline URTI & $10(4)$ & $8(3)$ & $9(4)$ & $27(4)$ & $9(2)$ & $4(<1)$ & II (2) & $24(1)$ \\
\hline Influenza & $6(2)$ & $2(<1)$ & $8(3)$ & $16(2)$ & $14(2)$ & $7(1)$ & $10(2)$ & $31(2)$ \\
\hline Back pain & $3(1)$ & $6(2)$ & $5(2)$ & 14 (2) & $7(1)$ & $7(1)$ & $10(2)$ & $24(1)$ \\
\hline Cough & $3(1)$ & $5(2)$ & $3(1)$ & II (I) & II (2) & $6(1)$ & $7(1)$ & $24(1)$ \\
\hline Oropharyngeal pain & $2(<1)$ & $6(2)$ & $3(1)$ & II (I) & - & - & - & - \\
\hline Nausea & $I(<1)$ & $7(3)$ & $3(1)$ & II (I) & - & - & - & - \\
\hline UTI & $4(2)$ & $3(1)$ & $4(2)$ & II (I) & - & - & - & - \\
\hline Sinusitis & $2(<1)$ & $3(1)$ & $5(2)$ & $10(1)$ & - & - & - & - \\
\hline Headache & $2(<1)$ & $5(2)$ & $2(<1)$ & $9(1)$ & $8(1)$ & $12(2)$ & $4(<1)$ & $24(1)$ \\
\hline Hypertension & $3(1)$ & $4(2)$ & $2(<1)$ & $9(1)$ & & & & \\
\hline Muscle spasms & $2(<1)$ & 0 & $4(2)$ & $6(<1)$ & - & - & - & - \\
\hline Bronchitis & - & - & - & - & $8(1)$ & $8(1)$ & $10(2)$ & $26(2)$ \\
\hline Pneumonia & - & - & - & - & $6(1)$ & $9(2)$ & $6(1)$ & $21(1)$ \\
\hline
\end{tabular}

Notes: ${ }^{a}$ For the MT subgroup, consistent with previous studies, the incidence of fatal cardiovascular SAEs was <1\% in all treatment groups, with three cardiac disorders observed in the UMEC/VI arm and one in the UMEC arm (one acute myocardial infarction in each treatment group). No fatal cardiovascular SAEs were observed in the MN subgroup.

Abbreviations: AE, adverse event; MN, maintenance-naïv; MT, maintenance-treated; SAE, serious adverse event; SAL, salmeterol; UMEC, umeclidinium; URTI, upper respiratory tract infection; UTI, urinary tract infection; VI, vilanterol.

treatment among this population. However, it should be noted that in the responder analyses for SAC-TDI, E-RS, SGRQ, and CAT, point estimates for the odds of responding were generally higher in MT then in MN patients. Furthermore, comparisons between the MN and MT subgroups should be made with caution, since the study was not powered for this analysis and there were potentially confounding differences between the subgroups at baseline. For example, a previous analysis of the EMAX trial has indicated that high SABA use may be a confounding factor when analyzing symptomatic treatment benefits between maintenance bronchodilators. ${ }^{19}$

The findings of this prospective analysis are generally consistent with previous post hoc analyses. A pooled analysis of $1056 \mathrm{MN}$ patients from two randomized controlled trials found statistically significant improvements in lung function and symptoms with the LAMA/LABA combination aclidinium bromide/formoterol fumarate compared with its monocomponents. ${ }^{15}$ Another pooled analysis of $533 \mathrm{MN}$ patients showed a significant improvement in trough $\mathrm{FEV}_{1}$ with UMEC/VI versus tiotropium that was numerically larger in the MN subgroup (146 mL) than in the ITT population (95 mL), as well as significant improvements in rescue medication use and CID risk. ${ }^{13}$ In a subgroup analysis of $678 \mathrm{MN}$ patients in the OTEMTO studies (powered to detect changes in the primary outcomes of SGRQ score and $\mathrm{FEV}_{1}$ ), greater improvements in lung function, SGRQ score, and TDI score were seen with tiotropium/olodaterol versus tiotropium monotherapy in MN patients. ${ }^{16}$ Furthermore, a pooled analysis of the Phase III PINNACLE studies showed significant lung function improvements with glycopyrrolate/formoterol fumarate versus its monocomponents in MN patients. ${ }^{17}$ Overall, the available data, including the results of this analysis, indicate that dual 
bronchodilator therapy provides incremental benefits with regard to lung function and symptoms when used as initial maintenance therapy.

A key strength of this study was the prospective, wellbalanced randomization of a well-characterized MN population. Patients in both subgroups were not receiving concurrent ICS, which can influence the efficacy of add-on therapy, particularly LABA, in patients with COPD. ${ }^{22,24}$ Certain study limitations should be considered; most importantly, the MN population represented only $31 \%$ of the overall study population and the study was not powered to detect treatment differences in the MN or MT subgroups. This is reflected in the inconsistency of the CID results, as in the $\mathrm{MN}$ population the reduction in risk of a CID favored UMEC/VI versus UMEC in two of the three definitions of a CID. A greater proportion of patients receiving monotherapy withdrew from the trial compared with patients receiving UMEC/VI, particularly in the UMEC arm, which may have reduced the observed treatment differences between dual and monotherapy due to a "healthy survivor" effect. ${ }^{25}$ UMEC/VI was compared with SAL rather than VI (the LABA component of $\mathrm{UMEC} / \mathrm{VI}$ ) in this post-registration trial because VI was not licensed as a monotherapy in any country. However, an indirect treatment comparison has suggested that SAL and VI are likely to have broadly similar effects on trough $\mathrm{FEV}_{1}$ and PROs including TDI. ${ }^{26}$ Additional studies that are powered to detect treatment differences for lung function and symptoms outcomes in $\mathrm{MN}$ patients are needed to further evaluate the benefits of initial maintenance therapy with dual versus mono bronchodilator initial maintenance therapy in symptomatic patients with COPD at low risk of exacerbations.

\section{Conclusions}

In this pre-specified subgroup analysis of patients with COPD in the EMAX trial, UMEC/VI provided clinically important additional improvements in lung function and symptoms and was well tolerated compared with UMEC and SAL monotherapy in MN patients, as well as in MT patients. There was an expected trend for greater improvement from baseline in lung function and rescue medication use in $\mathrm{MN}$ patients than in MT patients, for all treatments. Despite the small sample size in each subgroup, these findings provide support for the consideration of dual bronchodilator treatment early in symptomatic maintenance-naïve patients with COPD.

\section{Data Sharing Statement}

Anonymized individual participant data and study documents can be requested for further research from www. clinicalstudydatarequest.com.

\section{Ethics Approval and Informed Consent}

This study was performed according to the Declaration of Helsinki and received appropriate ethical approval (Supplementary Table S1). All patients provided written informed consent via a form signed at either the Prescreening or Screening visit.

\section{Acknowledgments}

Editorial support (in the form of writing assistance during development of the initial draft, assembling tables and figures, collating authors comments, grammatical editing, and referencing) was provided by Mark Condon, DPhil, and Meghan Betts, PhD, of Fishawack Indicia Ltd, UK, part of Fishawack Health, and was funded by GSK. ELLIPTA and DISKUS are owned by/licensed to the GSK group of companies.

\section{Author Contributions}

All authors made substantial contributions to conception and design, acquisition of data, or analysis and interpretation of data; took part in drafting the article or revising it critically for important intellectual content; agreed to submit to the current journal; gave final approval of the version to be published; and agree to be accountable for all aspects of the work. LB, FM, and EMK were involved in acquisition of data and data analysis and interpretation. IHB and CFV were involved in data analysis and interpretation. IPN, LT, PWJ, CC, and DAL were involved in study conception and design, and data analysis and interpretation.

\section{Funding}

This study was funded by GlaxoSmithKline (GSK study number: 201749 [NCT03034915]). GSK-affiliated authors had a role in study design, data analysis, data interpretation, and writing of the report and GSK funded the article processing charges and open access fee.

\section{Disclosure}

IHB, DAL, CC, and PWJ are employees of GSK and hold stocks and shares in GSK. IHB's current affiliation is Medical Emerging Markets, GSK, Brentford, Middlesex, UK. IPN was an employee of GSK at the time of the study, holds stocks and 
shares in GSK, and was a contingent worker on assignment at AstraZeneca. IPN's current affiliation is RAMAX Ltd, Bramhall, Cheshire, UK. LT is a contingent worker on assignment at GSK. FM has received research grants for participating in multicenter trials for AstraZeneca, Boehringer Ingelheim, GSK, Sanofi, and Novartis, and has received unrestricted research grants and personal fees from Boehringer Ingelheim, Grifols, and Novartis. LB has received honoraria for giving a lecture or attending an advisory board for Airsonett, ALK-Abello, AstraZeneca, Boehringer Ingelheim, Chiesi, GSK, Meda, Novartis and Teva. EMK has served on advisory boards, speaker panels or received travel reimbursement from for Amphastar, AstraZeneca, Boehringer Ingelheim, Connect Biopharma, GSK, Mylan, Novartis, Pearl, Sunovion, Teva, and Theravance and has received consulting fees from Cipla and GSK. CFV has received grants from AstraZeneca, Boehringer Ingelheim, Chiesi, GSK, Grifols, Novartis, and the German Federal Ministry of Education and Research (BMBF) Competence Network Asthma and COPD (ASCONET), and has received personal fees from AstraZeneca, Boehringer Ingelheim, Berlin Chemie/ Menarini, Chiesi, CSL Behring, GSK, Grifols, MedUpdate, Novartis, Nuvaira, and Teva. The authors report no other conflicts of interest in this work.

\section{References}

1. Dransfield MT, Bailey W, Crater G, Emmett A, O'Dell DM, Yawn B. Disease severity and symptoms among patients receiving monotherapy for COPD. Primary Care Respir j. 2011;20(1):46-53. doi:10.4104/ pcrj.2010.00059

2. Doyle T, Palmer S, Johnson J, et al. Association of anxiety and depression with pulmonary-specific symptoms in chronic obstructive pulmonary disease. Int $J$ Psychiatry Med. 2013;45(2):189-202. doi:10.2190/PM.45.2.g

3. Tsiligianni I, Kocks J, Tzanakis N, Siafakas N, van der Molen T. Factors that influence disease-specific quality of life or health status in patients with COPD: a review and meta-analysis of Pearson correlations. Primary Care Respir j. 2011;20(3):257-268. doi:10.4104/pcrj.2011.00029

4. Roche N, Chavannes NH, Miravitlles M. COPD symptoms in the morning: impact, evaluation and management. Respir Res. 2013;14 (1):112. doi:10.1186/1465-9921-14-112

5. Miravitlles M, Ribera A. Understanding the impact of symptoms on the burden of COPD. Respir Res. 2017;18(1):67. doi:10.1186/s12931017-0548-3

6. Mammen MJ, Pai V, Aaron SD, Nici L, Alhazzani W, Alexander PE. Dual LABA/LAMA Therapy versus LABA or LAMA Monotherapy for COPD: a Systematic Review and Meta-analysis in Support of the American Thoracic Society Clinical Practice Guideline. Ann Am Thorac Soc. 2020;17(9):1133-1143. doi:10.1513/AnnalsATS.201912-915OC

7. Oba Y, Sarva ST, Dias S. Efficacy and safety of long-acting beta-agonist/long-acting muscarinic antagonist combinations in COPD: a network meta-analysis. Thorax. 2016;71(1):15-25. doi:10.1136/thoraxjnl-2014-206732
8. Rodrigo GJ, Price D, Anzueto A, et al. LABA/LAMA combinations versus LAMA monotherapy or LABA/ICS in COPD: a systematic review and meta-analysis. Int $J$ Chron Obstruct Pulmon Dis. 2017;12:907-922. doi:10.2147/COPD.S130482

9. Calzetta L, Rogliani P, Matera MG, Cazzola M, Systematic Review A. With Meta-Analysis of Dual Bronchodilation With LAMA/LABA for the Treatment of Stable COPD. Chest. 2016;149 (5):1181-1196. doi:10.1016/j.chest.2016.02.646

10. Nici L, Mammen MJ, Charbek E, et al. Pharmacologic management of chronic obstructive pulmonary disease. an official American Thoracic Society Clinical Practice Guideline. Am J Respir Crit Care Med. 2020;201(9):e56-e69. doi:10.1164/rccm.202003-0625ST

11. National Institute for Health and Care Excellence (NICE). Chronic obstructive pulmonary disease in over 16s: diagnosis and management; 2019. Available from: https://goldcopd.org/wp-content /uploads/2019/12/GOLD-2020-FINAL-ver1.2-03Dec19_WMV.pdf. Accessed May 21, 2021.

12. Global Initiative for Chronic Obstructive Lung Disease (GOLD). Global strategy for the diagnosis, management and prevention of chronic obstructive pulmonary disease; 2021. Available from: https://goldcopd.org/wp-content/uploads/2019/12/GOLD-2020-

FINAL-ver1.2-03Dec19_WMV.pdf. Accessed May 21, 2021.

13. Maleki-Yazdi MR, Singh D, Anzueto A, Tombs L, Fahy WA, Naya I. Assessing Short-term Deterioration in Maintenance-naive Patients with COPD Receiving Umeclidinium/Vilanterol and Tiotropium: a Pooled Analysis of Three Randomized Trials. Adv Ther. 2016;33 (12):2188-2199. doi:10.1007/s12325-016-0430-6

14. Takahashi T, Ichinose M, Inoue H, Shirato K, Hattori T, Takishima T. Underdiagnosis and undertreatment of COPD in primary care settings. Respirology. 2003;8(4):504-508. doi:10.1046/j.14401843.2003.00501.x

15. Singh D, D'Urzo AD, Donohue JF, et al. An Evaluation Of Single And Dual Long-Acting Bronchodilator Therapy As Effective Interventions In Maintenance Therapy-Naive Patients With COPD. Int J Chron Obstruct Pulmon Dis. 2019;14:2835-2848. doi:10.2147/ COPD.S217710

16. Singh D, Maleki-Yazdi MR, Tombs L, Iqbal A, Fahy WA, Naya I. Prevention of clinically important deteriorations in COPD with umeclidinium/vilanterol. Int $J$ Chron Obstruct Pulmon Dis. 2016;11:1413-1424. doi:10.2147/COPD.S101612

17. Zheng J, Xu JF, Jenkins M, Assam PN, Wang L, Lipworth BJ. Glycopyrrolate/formoterol fumarate metered dose inhaler for maintenance-naïve patients with chronic obstructive pulmonary disease: a post-hoc analysis of the randomized PINNACLE trials. Respir Res. 2020;21(1):69. doi:10.1186/s12931-020-1332-3

18. Maltais F, Bjermer L, Kerwin EM, et al. Efficacy of umeclidinium/ vilanterol versus umeclidinium and salmeterol monotherapies in symptomatic patients with COPD not receiving inhaled corticosteroids: the EMAX randomised trial. Respir Res. 2019;20(1):238. doi:10.1186/s12931-019-1193-9

19. Maltais F, Naya I, Vogelmeier CF, et al. Salbutamol use in relation to maintenance bronchodilator efficacy in COPD: a prospective subgroup analysis of the EMAX trial. Respir Res. 2020;21(1):280. doi:10.1186/s12931-020-01451-8

20. Lange P, Halpin DM, O'Donnell DE, MacNee W. Diagnosis, assessment, and phenotyping of COPD: beyond FEV(1). Int $J$ Chron Obstruct Pulmon Dis. 2016;11:3-12. doi:10.2147/COPD.S85976

21. Kaplan A, Thomas M. Screening for COPD: the gap between logic and evidence. Eur Respir Rev. 2017;26(143):143. doi:10.1183/ 16000617.0113-2016

22. Naya I, Tombs L, Lipson DA, Boucot I, Compton C. Impact of prior and concurrent medication on exacerbation risk with long-acting bronchodilators in chronic obstructive pulmonary disease: a post hoc analysis. Respir Res. 2019;20(1):60. doi:10.1186/s12931-019$1027-9$ 
23. Punekar YS, Sharma S, Pahwa A, Takyar J, Naya I, Jones PW. Rescue medication use as a patient-reported outcome in COPD: a systematic review and regression analysis. Respir Res. 2017;18 (1):86. doi:10.1186/s12931-017-0566-1

24. Sion KYJ, Huisman EL, Punekar YS, Naya I, Ismaila AS. A Network Meta-Analysis of Long-Acting Muscarinic Antagonist (LAMA) and Long-Acting $\beta 2$-Agonist (LABA) Combinations in COPD. Pulm Ther. 2017;3(2):297-316. doi:10.1007/s41030-017-0048-0
25. Vestbo J, Anderson JA, Calverley PMA, et al. Bias due to withdrawal in long-term randomised trials in COPD: evidence from the TORCH study. Clin Respir J. 2010;5:44 49. doi:10.1111/j.1752-699X.2010.00198.x

26. Donohue JF, Betts KA, Du EX, et al. Comparative efficacy of long-acting beta2-agonists as monotherapy for chronic obstructive pulmonary disease: a network meta-analysis. Int J Chron Obstruct Pulmon Dis. 2017;12:367-381. doi:10.2147/COPD.S119908

\section{Publish your work in this journal}

The International Journal of COPD is an international, peer-reviewed journal of therapeutics and pharmacology focusing on concise rapid reporting of clinical studies and reviews in COPD. Special focus is given to the pathophysiological processes underlying the disease, intervention programs, patient focused education, and self management protocols. This journal is indexed on PubMed Central, MedLine and CAS. The manuscript management system is completely online and includes a very quick and fair peer-review system, which is all easy to use. Visit http://www.dovepress.com/testimonials.php to read real quotes from published authors. 